\title{
LIFE SUPPORT SYSTEMS INTEGRATION
}

By Warren D. Hypes

NASA Langley Research Center Langley Station, Hampton, Va.

Presented at the Conference on Bioastronautics at Virginia Polytechnic Institute

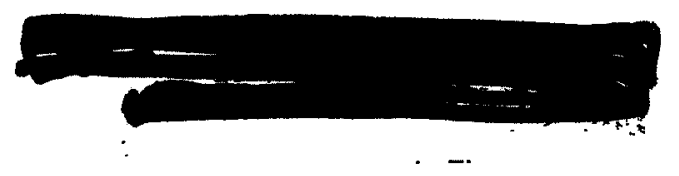

Blacksburg, Virginia

August 14-18, 1967

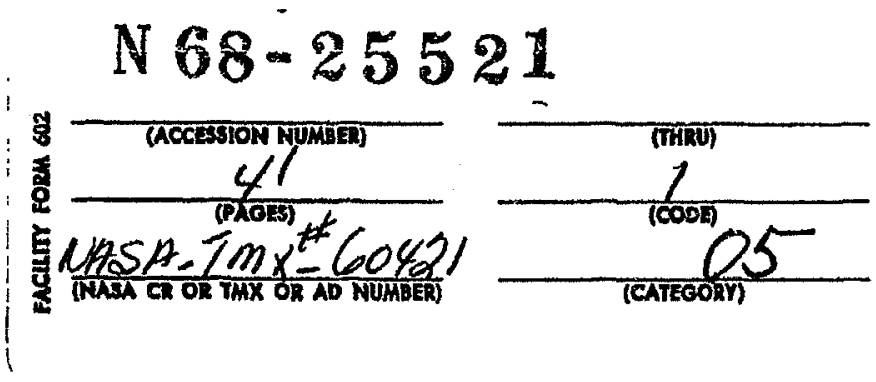




\title{
LIFE SUPPORT SYSTEMS INTEGRATION
}

By Warren D. Hypes

NASA Iangley Research Center

\author{
SUMMARY
}

Achieving an optimized design of regenerative Environmental Control and Life Support (EC/IS) Systems requires integration at three levels: (1) subsystem, (2) system, and (3) total spacecraft.

Two types of subsystem level integration are desirable. One type is process integration which interfaces mass transfer, reaction rate control, and phase separaticn techniques. A second type is operational mode integration which interfaces selected techniques and design schemes for producing system operationsl flexibility.

System level integration is paced by thermal balance considerations. These considerations involve the techniques of supplying heat to the endothermic processes and coolant to the system hardware and cabin environment.

At the total spacecraft level, integration occurs nost intimately between the EC/LS System, the Power System, and the Thermal Control System. The common denominator for these three Systems is energy in the form of heat.

Tests have been conducted on a full-scale, research model integrated system. The tests hav indicated that the regenerative processes are feasible but that extensive development of subsystems hardware is necessary before regenerative systems can be applied to flight vehicles.

\section{INTRODUCTION}

During the past 10 years, government research laboratories and private industry have been cooperating in research efforts directed toward finding techniques and processes that can regenerate useful products from the waste products available in manned spacecraft. Most of $t$ jese research efforts have consisted of a study of a promising physicochemicai. technique followed by the development of a laboratory model which was used to demonstrate feasibility of the technique. The majority of the laboratcry models were individual units designed for specific inlet conditions of mass flow, purity of flow, pressure, and temperature. These inlet conditions were accurately controlled and, therefore, the process efficiencies were not subject to frequent change due to variations in iniet conditions. This type of research is necessary to uncover and evaluate new approaches to regenerative life support processes; however, the true feasibility of the technique and embodying component cannot be established until. it has beis integrated into a total system where its inlet conditions are established by the output of a previous component. To demonstrate feasibility as a par of an integrated EC/LS System, the component must he integrated into 
such a system for functional checkout. Integration within regenerative EC/LS Systems and between EC/LS Systems and other systems aboard a spacecraft has been studied and discussed many times during the past 5 years. Several excellent reports and papers (refs. 1 to 4) treat the subject in technical depth; however, actual integration of hardware into working models has been accomplished on a very limited scope. One such accomplishment was the cooperative program between the National Aeronautics and Space Administration and General Dynamics/Convair which led to the research model Integrated life Support System (IISS) now being researched at the Langley Research Center in Hampton, Virginia. This research tool is a valuable aid in an ongoing research program to isolate, define, and solve the technical and practical problems associated with integration of regenerative EC/LS Systems at the subsystem, system, and total spacecraft level. Observations made during the conceptual design, detailed design, and fabrication phases and experiences gained during experimental phases of the ILSS program have provided the baseline for this discussion of Life Support Systems Integration.

\title{
DEFINITION OF INTEGRATION
}

Webster's Dictionary gives several definitions of the word integrate. The first three definitions given can be taken as a combined definition of the word when applied to regenerative EC/LS Systems. The definitions are (1) to form into a whole, (2) to unite with something else, and (3) to incorporate into a larger unit.

Each of the definitions describes a separate level of the total integration procedure. The first definition - to form into a whole - describes integration at the subsystem level. At this level, components and units are integrated into subsystems wrich have specific functions such as the recovery of oxygen from carbon dioxide and recovery of potable water from waste water. The second definition - to unite with something else - describes integration at the system level. At this level, subsystems such as those for water recovery, oxygen recovery, waste management, etc., are integrated into a complete EC/LS System which has the broad function of sustaining life. The third definition - to incorporate into a larger unit - describes integration at the total spacecraft level. At this level, the EC/LS System and other systems such as the Electrical Power and Thermal Control Systems are integrated into the overall optimized spacecraft concept. Each of these levels of integration must occur if the resulting $\mathrm{EC}^{/ /} \mathrm{S}$ System is to be truly integrated.

\author{
FOCAL POINT FOR DISCUSSION - THE LANGLEY INTEGRATED
}

\section{LIFE SUPPORT SYSTEM (IIISS)}

The ILSS is shown as an artist's concept in figure 1. Figure 2 is a composite photograph of the regenerative EC/LS System within the carbon steel test bed. The system was designed to support, a four-man crew in a zero-gravity environment for a period of 1 year. Resupply at 60- to 90-day intervals was 
assumed. This design point mission model was chosen as typical of the missions likely to evolve in the NASA manned space program. Studies also revealed that the regenerative EC/LS System required to support the mission model would embody techniques applicable to a wide range of extended missions.

Since the IISS technology has a broad application and since its development and testing represent $a$ unique step in the evolution of integrated EC/LS System technology, it will be used as a focal point for the following discussion.

\section{INTEGRATION AT SUBSYSTEM LEVEL}

\section{Atmosphere Control Subsystem}

The atmosphere control subsystem is one of the major integrated subsystems in the IISS. It is within this subsystem that oxygen is recovered from carbon dioxide, makeup gases are added, and the atmosphere is purified to maintain a habitable environment. The oxygen recovery portion of this subsystem is a good example of process integration at the subsystem level.

Figure 3 is a schematic of the oxygen regeneration process in the Bosch mode of operation. A general, but summarizing, analysis of the integration problem can be made by observation of the materials balance depicted on the figure. According to the theoretical materials balance, it is possible to recover $7.48 \mathrm{lb} /$ day of oxygen (four-man requirement at an average of 150 percent basal metabolism rate) from $9.28 \mathrm{lb} /$ day of carbon dioxide and $0.82 \mathrm{lb} /$ day of makeup water. The theoretical balance is based on the stoichiometry of the two basic chemical reactions involved, carbon dioxide reduction:

$$
\mathrm{CO}_{2}+2 \mathrm{H}_{2} \rightarrow 2 \mathrm{H}_{2} \mathrm{O}+\mathrm{C}
$$

and electrolysis of water:

$$
2 \mathrm{H}_{2} \mathrm{O} \rightarrow 2 \mathrm{H}_{2}+\mathrm{O}_{2}
$$

The integration problem is one of controlling the chemical reactions and hardware operational sequences to achieve the theoretical yield of oxygen. Some of the details of the general integration problem can be pointed out by a discussion of the units that make up the oxygen recovery Ioop.

Carbon dioxide concentration unit. - The first unit in the loop is the regenerable carbon dioxide concentrator shown in figure 4. The concentrator receives a continuous flow of approximately 30 cubic feet per minute of air direct from the cabin air-conditioning unit. The flow to the concentrator exits the air-conditioning unit immediately downstream of the heat exchanger and air-water separator. At that location, the air is at its lowest temperature and dewpoint which are favorable conditions for the adsorption phenomenon 
that follows. Adsorption occurs in silica gel and artificial zeolite beds. The silica gel beds remove remaining traces of moisture to a low dewpoint of approximately $-70^{\circ} \mathrm{F}$, and the zeolite beds selectively adsorb 40 to 60 percent of the carbon dioxide in the airstream. During operation, one silica gel and one zeolite bed are adsorbing while a sccond pair of beds is being desorbed. The silica gel bed is being desorbed be $3 \mathrm{k}$ into the cabin airstream to prevent loss of water. The desorbed carbon dioxide is stored in an accumulator tank from which it is available for reduction in the carbon dioxide reduction unit. The energy for desorbing the molecular sieve beds is being supplied as heat by a waste heat process circuit originating from a simulated radioisotope, Brayton cycle Power System. The hot fluid enters the desorbing zeolite bed at approximately $375^{\circ} \mathrm{F}$. The concentration unit also contains a cooling fluid circuit for maintaining proper thermal conditions in the adsorbing beds and associated heat exchangers.

There are two primary integration int $\epsilon_{L^{2}}-2$ aces between the concentrator and other units within the oxygen recovery loop. The air exiting the airconditioning unit and entering the concentrator must not contain moisture in excess of that present in saturated air at $55^{\circ} \mathrm{F}$. If excess moisture is present, the s:lica gel beds will become oversaturated and they will pass moisture into the zeolite beds. If this occurs, it will destroy the zeolite bed's capacity to adsorb carbon dioxide. Therefore, the temperature-moisture relationship of the dir exiting the air-conditioning unit must be closely controlled when an air-conditioning unit is integrated with a zeolite type carbon dioxide concentrator. Another integration interface involves the purity of the carbon dioxide desorbed from the concentrator and available for chemical reduction. The most common impurity in the carbon dioxide accumulation tank is nitrogen which is present in the "air" trapped in the free air spaces of the canisters containing the zeolite. There is also some unconfirmed evidence that the zeolite material may be adsorbing nitrogen; however, the majority of it can be attributed to residual air. If the carbon dioxide purity in the accumulator falls below approximately 98 percent, sufficient nitrogen can be introduced into the carbon dioxide reduction unit to require remedial action. The purity in the accumulator tank is affected by both adsorption and desorption cycles but perhaps most directly by the initial portion of the desorption cycle. The residual nitrogen (air) in the free air spaces of the desorbing canister is driven off first and if desorbed to the accumulator, a low carbon dioxide purity would result. It is therefore necessary to desorb the canister back to the unit intake during early minutes of the desorption cycle. As the desorbing gas becomes essentially pure carbon dioxide, it is desorbed to the accumulator tank from which it is made available to the reduction unit.

Carbon dioxide reduction unit. - The second unit in the oxygen recovery loop is the carbon dioxide reduction unit shown in figure 5. Carbon dioxide is delivered to the unit from the accumolator tank through a solenoid valve which is actuated based on measurement of carbon dioxide concentration in the reactant gas stream as sensed by an infrared analyzer. It is mixed with hydrogen from the water electrolysis unit and passed into a reactor where it is reduced over iron catalyst plates at a temperature of approximately $1100^{\circ} \mathrm{F}$. The reaction is the Bosch process represented by the chemical equation:

$$
\mathrm{CO}_{2}+2 \mathrm{H}_{2} \rightarrow 2 \mathrm{H}_{2} \mathrm{O}+\mathrm{C}
$$


The carbon that results from the reaction is a waste product and is collected in a filter which must be periodicaily replaced. The product gases are then cooled, and the steam produced by the reaction is condensed and separated from the gas stream by means of a passive, capjillary action type separator. The gas stream contains unreacted carbon dioxide and hydrogen, uncondensed water vapor, and carbon monoxide and methane from secondary reactions. After being enriched with additional carbon dioxide and hydrogen when necessary, the gas stream is recycled to the reduction unit. The recycle flow is an advantage of the Bosch proce $s$ because unreacted gases and uncondensed water vapor are not lost. Consequently, the completeness of the reduction and water condensation processes during any short interval of time is not crjical.

Integration interfaces between the reduction unit and other units in the oxygen recovery loop and the overall atmosphere control subsystem are numerous. One previously mention $I$ is the purity of carbon dioxide from the carbon dioxide concentration unit. Ise common impurity, nitrogen, will decrease the process rate when introduced into the reactor by lowering the partial pressures of the reactants. In order to remove the nitrogen, a flow of approximately $2 \mathrm{cc} / \mathrm{min}$ is bled from the recycle loop back into the cabin. Since the bleed flow will also contain carbon monoxide anc methane from secondary reactions, it must be bled through a high-temperature catalytic oxidizer. It was also expected that additional carbon monoxide and methane would be introduced direct into the cabin air through leaks ir the plumbing and seals of the reduction unit. Test experience has confirmed the expected leakage. The leakage, however, has been much greater in magnitude than expected. Leakage rates as high as 130 to $170 \mathrm{cc} / \mathrm{min}$ have been experienced. Because of the leakage, it has been necessary to periodically operate two catalytic burners simultaneously. This situation is undesirable because of the increased demand for oxygen in the oxidation process and the increase in requirements for electrical power.

Arother integration interface involving reactant gas feed is present between the reduction unit and the water electrolysis unit. It involves the movement of hydrogen between the two units. According to the theoretical materials balance shown in figure 3, maintenance of a stoichiometric Bosch process at the four-man oxygen regeneration level will produce excess hydrogen; the excess being supplied in the makeup water that is required for oxygen generation. The excess has not been confirmed by actual tests to date because units of the oxygen recovery loop have not mechanically functioned for long enough periods of time to permit an attempt at a materials balance. The anticipated problem of controlling the hydrogen feed to the reduction unit in stoichiometric ratis with the carbon dioxide feed does not appear to be a severe integration problem as expected. Tests of the reduction unit reported by Clark and Holmes (ref. 5) indicate that the rate of water formation is relatively insensitive to recycle gas hydrogen/carbon dioxide volume ratios ranging from 3.0 to 9.0 . This observation has led to the development and testing of an automatic feed gas approach which uses simple con rol techniques. Carbon dioxide from the accumulator is delivered at $3.5 \mathrm{psig}$ to a solenoid valve which opens and closes on signal from a low and a high setting on an infrared carbon dioxide analyzer. The analyzer is detecting the amount of carbon dioxide in the recycle loop and, thus, a specific amount (ratio of carbon dioxide to total gas) of carbon dioxide is maintained in the recycle gas. Hydrogen is delivered from the 
electrolysis unit to a pressure regulator set at 3.0 psig. When the recycle gas loop pressure falls below 3.0 psig inc ating the need for additional reactants, the valve opens and admits hydrogen until the pressure again reaches 3.0 psig. This technique assures eufficient quantities of gases for the reaction which will take place stoichiometrically over a long period of time although for any given shcrt period of time, an exact stoichiometric feed is not necessary.

The inclusion of an alternate reduction unit in the oxygen recovery loop is an integration feature of the ILSS. If trouble occurs in the Bosch reactor, the reactant gases can be directed to a low-temperature Sabatier reactor which shares some common plumbing with the Bosch reactor. Figure 6 is a schematic of the oxygen regeneration process in the Sabatier mode. In the Sabatier reactor, the carbon dioxide is reduced by hydrogen over a nickel catalyst at a tempera-. ture of approximately $500^{\circ} \mathrm{F}$. The reaction is represented by the chemical equation

$$
\mathrm{CO}_{2}+4 \mathrm{H}_{2} \rightarrow \mathrm{CH}_{4}+2 \mathrm{H}_{2} \mathrm{O}
$$

There is a basic differesce between the Bosch and Sabatier process materials balance. The Bosch permits reduction of all the available carbon dioxide but because of the increased use of hydrogen in the Sabatier, only a portion of the carbon dioxide can be reduced. From an integration standpoint, there are some additional differences. Accurate control of the hydrogen-to-carbon-dioxide-feed ratio that was experimentally determined not to be a problem with the Bosch is a problem with the Sabatier. The Sabatier reactor does not have a recycle loop because of the need to continually vent the methane. Thus, reactant gases that are not converted on a single pass and uncondensed water vapor are lost overboard along with the methane. Loss of carbon dioxide less than the $3.131 \mathrm{~b} /$ day excess shown in figure 6 does not create a severe penalty but loss of the hydrogen and water vapor does penalize the Sabatier process. Compounding this problem is the experimental evidence that better water yields are obtained with feed ratios that are hydrogen rich. If the process is hydrogen rich, the unreacted hydrogen will also be lost overboard.

The integration problem of generation and control of carbon monoxide has not been experienced with the Sabatier. The generation problem is inherently less with the Sabatier process and the leakage problem is alleviated because of the lack of a recycle gas loop and rotating catalyst drive mechanisms.

Water electrolysis unit. - The third unit in the integrated oxygen recovery loop is the water electrolysis unit shown in figure 7. The unit includes three module: , each of which contains 16 cells. The cells contain a 25-percent solution of sulfuric acid electrolyte and water between two ion-exchange membranes. The electrodes are made by coating the outer surfaces of the membranes with a platinum black catalyst powder in contact with a current distributing screen. The oxygen produced at the positive electrodes is released into the cabin for crew consumption. The hydrogen evolved at the negative electrodes is used in the reduction unit. The integration interface of hydrogen flow between the water electrolysis unit and the reduction unit has been described previously. 
Another integration interface between these two units involves the purity of the water as generated by the reduction versus the purity requirement as dictated by the electrolysis unit. The water management subsystem also interfaces into the purity problem because of the makeup water that it adds to the total required for electrolysis. This water purity integration interface has not been defined. To date, all $f$ sed water to the electrolysis unit has been distilled water.

\section{Water Management Subsystem}

The ILSS water management subsystem is a good example of integration of operational modes at the subsystem level. It is within this subsystem tiat usable water is recovered from urine, wash water, and humidity condensate. This subsystem also serves as a collection, holding, and Jispensing function tur water throughout the entire system. The complete sussystem is shown in figure 8.

Wick-type evaporation units. - The water recovery process occurs in the wick-type evaporation units, one of which is shown in figure 9. A flow of air heated to tempsratures between $120^{\circ}$ to $180^{\circ} \mathrm{F}$ is passed over a wick saturated with waste liquids. The water in the liquids is vaporized, condensed, and separated from the airstream. The separation is accomplished by a turbine-driven, centrifugal separator. The water is then pumped to the holding tanks for purity analysis. The waste solids remain in the wick. The airstream is reheated and passed into the wick for another cycle. Chromic and sulfuric acid pretreatment chemicals are added to the waste water prior to processing to lower the $\mathrm{pH}$, fix ammonia, and prevent the growth of micro-organisms.

Multifiltration unit.- A multifiltration unit is included in the system as a standby for emergency mode operation. This unit uses activated charcoal filters and ion-exchange resin beds to process humility condensate to potable water. The unit is sized for a 17-day capacity.

Operational mode. - The two types of recovery units discussed are capable of three modes of operation. In the normal processing mode, the total system water balance is as follows:

Water required:

Quantity,

Drinking and food preparation .............. $1 \mathrm{~b} /$ day $/ 4$ men

Wash water .....................

30.0

Electrolysis makeup.................

13.2

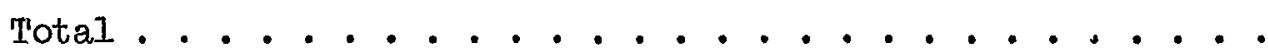

$\frac{0.8}{44.0}$

Water recovered:

Urine water ......................

1.3 .2

Wash water ... . . . . . . . . . . 13.2

Humidity condensate............... 19.6

Total .......................... 46.0 
f. schematic of the normal processing mode is shown in figure 10. As shown in the figure, one evaporation unit is processing urine to wash water and the other unit is processing wash water and humidity condensate to potable water. Thus, to process urine to potable water two process cycles are required.

A secondary mode, the minimum continuous mode shown in figure 11 , is provided by silightly oversizing the evaporation units so that each unit can process all three types of waste waters. In this mode of operation, one evaporation unit has failed and the other unit is processing urine, humidity condensate, and a portion of the wash water. There is only one process cycle from urine to potable water, and the amount of water for personas inggiene is reduced.

The third mode of operation, the emergency mode, is represented in figure 12. In this mode, only the humidity condensate is process ad by the emergency multifiltration unit and makeup water is added from the stored supply. Water for washing is no longer available. This design concept and arrangement of the water management subsystem is an example of integration of operational modes to provide redundancy, step degradation, and emergency capability.

\section{Other ILSS Subsystems}

The remaining subsystems are not good examples of integration within tinemselves but are a necessary part of a following discussion on integration at the system level. Therefore, in preparation for the later discussion, they are described briefly as follows:

Nutritional support subsystem. - Nutritional support is provided by freezedried, stable-conventional, and frozen foods. The foods are stored, prepared, and dispensed with the aid of the console shown in figure 13 and a suppl'mentary freezer not currently a part of tise system. Preparation of the food required warni water at $180^{\circ} \mathrm{F}$ and cool water at $40^{\circ} \mathrm{F}$ for reconstitution of the dried foods. The reconstitution takes place in small plastic packages which are used as dispensing aids.

Waste management subsystem. - The waste management subsystem prorides for the collection of all wastes, the processing of solid body wastes, and the storage of waste solids for the entire systern. The current configuration of the waste collection and processing unit is shown in figure 14. Urine is $c$ lected in a relief tube with the aid of a small flow of cabin air. After $k$ separated from the airstream by a motor-driven centrifugal separator, the $u_{i}$ is pumped to the water management subsystem for processing. The airstream is returned to the cabin. Fecal material is collected in a conical paper filter backed by a permeable hydrophobic polymer fabric. During the collection process a small flow of cabin air is pulled into and through the collection cones. The flow transports noxious odors to activated charcoal filters where the airflow is cleaned prior to returning it to the main cabin airstream. The collection cones containing the fecal material and cleaning tissue are manually transferred to a processing canister in which it is vacuum dried by a simulated space vacuum with the aid of waste heat from the process heat circuit. The dried material is then placed in a nonpermeable bag and stored in one of the large storage contajners placed adjacent to the collection unit. The vacuum-drying canisters 
anc: the storage containers are also used to process solid waste materials from the nutritional support and personal hygiene subsystems.

The functions provided and the quantity of wastes handled by the waste management subsystem are as follows:

Waste

Feces

Urine

Refuse:

Food and Packaging

Personal hygiene

Carbon
System function

Collection, processing, storage

Collection, transfer

rocessing, storage

" scessing, storage

- orage
Quantity handled, Ib/day/4.men

\section{3}

13.2

1.6

0.5

2.5

Personal hygiene subsystem.- The personal hygiene subsystem provides sponge bathing and conventional dental and shaving facilities. Warm water treated with benzalkonium chloride at a dilution of 1:2000 is furnished for body cleansing and rinsing oi" personal hygiene aids. A cylindrical chamber with a thumboperated removable piston provides a container for wetting, drying, and cleansing of the sponges. Dental cleansing is provided by a conventional toothbrush and ingestible dentifrice. Shaving is accomplished with an electric razor. In a flight system, the razor would be modified to include a small induc: :on blower and whisker collection bag.

Thermal control subsystem. - The thermal control subsystem includes three integrated fluid circuits. They are the process heat circuit, the primary coolant circuit, and the cabin air circuit. They : discussed in more detail in the next section of the paper.

\section{INTEGRATION \&T SYSTEM LEVEL}

A complete treatment of integration of the ILSS at the system level would involve a discussion of every component in every subsystem. Fach contribute to sume extent to the overall integration procedure. There is one subsystem, however, that is the key to system level integration. That subsystem is the thermal control subsystem wnich includes three integrated fluid circuits; the process heat circu 5 , the primary coolant circuit, and the cabin air circuit. A highly simplified schematic of the integration of these three circuits is shown in figure 15.

\section{Process Heat Circuit}

One of the candidate Power Systems for use on extended mission spacecraft is the dynamic Brayton cycle radioi sotope system. The ILSS was designed around a typical extended mission spacecraft concept which included this type of Power System. During operation of the Power System it rust reject large quantities 
of waste heat. By using the waste heat to supply energy for the regenerative physicochemical processes, the requirement for energy supplied directly by electrical power Irom the spacenr ${ }_{\text {s }}$ ft Power System can be reduced. In the ILSS, a commercial heating cart deliver a simulated waste heat load to the EC/LS System by means of a silicone fluid at a temperature of $375^{\circ} \mathrm{F}$ at the inlet to the system. Approximately 15,800 Btu/hr (4.6 kWt) of waste heat energy is delivered to the EC/IS System by the process heat circuit shown schematically in figure 16. In the circuit, the EC/LS System components are arranged for the most effective utilization of the waste heat by placing components requiring the highest fluid temperatures upstream of the others and by placing components with cyclic heating requirements, such as the carbon dioxide concentrator, on separate branch circuits. Although cryogenic stores heat exchangers were not installed in the ILSS, provisions were made for them in the system design. These heat exchangers were located on a separate branch of the process heat circuit to permit the total heat transport fluid to be diverted to them if needed for emergency repressurization.

The utilization of $t_{i}$ ie waste heat is an example of optimization by integration; however, it also ereates integration problems which have not been completely solved. Absolute containment of the hot fluid is a difficult tasik. Containment is further complicated by the need to repeatedly break and remake fittings when .omponents are renoved for maintenance. Another problem with the integraled process heat circuit is the one of controlling the flow through the EC/IsS System. Balancing vaives, orifices, and bypass lines must be provided to ensure proper fluid distribution through ell units when single or multiple units are turned off or adjusted. Control in the ILSS is accomplished manually and it requires considerable attention. If waste heat process circuits are to be used in flight systems, a technique for automatir contivi must be developed.

\section{Primary Coolant Circuit}

A primary coolant circuit utilizing a mixture of propylene glycol and water further integrates the EC/Ls System. A schematic of the circuit is shown in figure 17. An excerpt from NASA Contractor Report, NASA CR-614 (ref. 6), describes the integration:

The water chiller, cabin air heat exchanger $\mathrm{A}$, and $\mathrm{CO}_{2}$ reduction unit ail reuire low-temperature coolant for condensing or chilling operations and were located in parallel circuits immediately downstream of the fluid cooling and pumping unit. Heat exchanger B was installed in the fluid circuit immediately downstream of heat exchanger $A$ so that heat exchanger $B$ receives full coolant flow at a maximum temperature of $46^{\circ} \mathrm{F}$.

The electrolysis unit was located in a bypass circuit downstream of heat exchanger $B$. This location permits the unit to reseive a constant coolant flow at a temperature of approximately $65^{\circ} \mathrm{F}$. A fixed orifice was installed in t" main circuit parallel to the electrolysis unit to divert the required coolant flow to the unit. 
The water recovery units and the coolant-fluid heater (electronic equipment simulator) were installed in series downstream of the water chiller to take advantage of the low-temperature coolant leaving the chiller.

The $\mathrm{CO}_{2}$ concentration unit, which has large cyclic cooling requirements, was located downstream of the $\mathrm{CO}_{2}$ reduction unit to minimize its effect upon the remainder of the circuit.

This distribution circuit permits each component to receive coolant at the lowest available temperature without producing excessively high circuit-pressure drop or increasing the total fluid-flow rate above that required to satisfy the cooling requirements of the low-temperature units.

Balancing valves are installed in all parallel branch circuits to allow flow rate adjustment. Enough calibrated flow-measurement orifices have been installed to permit direct or indirect (sum-anddifference) determination of the coolant flow rate to each key comportent in the circuit.

Integration problems experienced with this circuit are similar to those experienced with the process heat circuit. Originally the primary coolant circuit used a fluorocarbon liquid that was difficult to contain. Upon leaking it Would quickly evaperate. Thus, the point of leakage was difficult to locate. After changing to glycol and water, the leakage problem was reduced. Experience has indicated that the entire problem of maintaining an automatic balanced flow of heating and cooling fluids throughout an integrated systeni with cyclic thermal conditions will be a difricult one for which to find an optimum solution.

\section{Cabin Air Circuit}

The cabin air circuit shown schematically in figure 18 provides a transfer function for many of the materials associated with the process loops; however, as part of the thermal control subsystem, its primary function is to transfer sensible and latent heat loads from the cabin atmosphere to the cabin air-heat exchanger. The cabin environment is maintained at a selecied temperature in the range from $68^{\circ} \mathrm{F}$ to $80^{\circ} \mathrm{F}$ and a relative humidity between 40 and 60 percent. Condensation and removal of excess humidity is accomplished in the cabin air circuit with the heat exchanger and a passive type of air-water separator which utilizes capillary action across porous plates as the phase separation technique.

\section{INTEGRATION AT TOTAL SPACECRAFT LEVEL}

The integration of $\dot{a}$ regenerative $\mathrm{EC} / \mathrm{LS}$ System with the total spacecraft is an action that does not occur independently or at any specific time during the spacecraft design. It occurs simultaneously with the development of the total spacecraft concept. Many of the design requirements that are imposed on the 
EC/LS System are established by the mission model, gross features of the spacecraft model, and crew model that are initially fixed by the mission to be flown and the capability of propulsion systems. The elements of the models include interfaces vetween the EC/IS System and other spacecraft disciplines such as configuration and structure, guidance and control system, and mission profile; however, the best example of integration at the total spacecraft level is the interiace between the EC/LS System, the Power Generation System, and the Thermal Control System. This interface can be observed by an examination of figure 19. Figure 19 is a summary of the ILSS heat load. Note that the regenerative EC/LS System demands considerable energy, $37,248 \mathrm{Btu} / \mathrm{hr}, 1$ to drive the processes. In a nonintegrated spececraft, the energy would be delivered to the regenerative processes as heat from resistance heaters. In an integrated spacecraft with a dynamic radioi sotope Power System, a large portion of the energy can be supplied by heat that is waste from the Power System. Thus, the endothermic EC/LS System can act as a heat sink for the Power System. As a result, the overall weight and size of the spacecraft can be reduced by reducing the weight and size of the Power System or the savings in power can be used for other purposes such as conductirig onboard scientific experiments.

A11 integration interiaces between the EC/LS System and the total spacecraft cannot be as clearly defined or so quickly reduced to a numerical tradeoff as can the EC/LS System-Power System-Thermal Control System interface. The reliability requirements for extended mission spacecraft make inflight maintenance necessary, EC/LS Systems must therefore be designed and arranged for access. One approach to this problem that is currently receiving study is the one of modularizing the $\mathrm{EC} / \mathrm{LS}$ System. In addition to easing maintenance problems, modularizing may provide reliability through redundancy. The final arrangement of a single or modular EC/LS System will undoubtedly affect configuration of the total spacecraft.

TEST RESULTS

The ILSS used as a focal point for the discussion of life support system integration has been used to isolate and define some of the technological and practical problems that must be solved before regenerative systems can be applied to flight vehicles. It is not within the scope of this paper to present and discuss all of the test results obtained to date; however, it is appropriate to present a few of the most significant results. The cumulative engineering test hours on the ILSS units are:

$$
\text { Unit }
$$

$\mathrm{CO}_{2}$ Concentration

$\mathrm{CO}_{2}$ Reduction:

Bosch

Sabatier

$\mathrm{H}_{2} \mathrm{O}$ Electrolysis

Catalytic Burners

Evaporation (water)

\section{Total houss}

1441

869

436

1300

2178

760

$132,528 \mathrm{Btu} / \mathrm{hr}-11,080 \mathrm{Btu} / \mathrm{hr}+19,444 \mathrm{Btu} / \mathrm{hr}-3,600 \mathrm{Btu} / \mathrm{hr}$ (see fig. 19). 
The cumulative times include periols of independent operation and periods of operation as part of the integrated system. Four integrated system tests have been conducted, and they are outilined below:

24-hour functional evaluation - unmanned, coors open

7-day integrated system - intermittently manned, doors closed

3-day integrated system - manned (3-crews), doors closed

4-day integrated system - manned (3-crews), doors closed

Some of th: most significant results are discussed briefly as follows:

Carbol Dioxide Concentration Unit

This unit has functioned well. It has continued to maintain the cabin carbon dioxide percentage nea: the 0.5-percent design point. During periods when the unit is functioning properly, the purity of carbon dioxide delivered to the accumulator tank has reached 99 percent. The majority of the difficulties experienced with the unit have been mechanicat failures of valves and valve actuators. When valve failures occur, they have immediate and significant effect on the performance of the unit. Only one hed poisoning has occurred. Early in the subsystem checkout program, coolant flow to the cabin air heat exchanger was erroneously bypassed around the heat exchanger. This permitted excessive moisture to enter the silica gel beds and they became oversaturated. Attempts to dry down the beds failed and the silica gel had to be replaced.

Bosch Carbon Dioxide Reduction Unit

The performance of the Bosch reduction process anc the resulting water yield has been encouraging. In addition, the anticipated integration problem of controlling feed gas ratios has not proved to be a difficult problem. A satisfactory solution to this problem was developed and has been discussed in an earlier section of the paper.

The successes, however, have been overshadowed by two problem areas.

1. Carbon transport and removal - The problem of removal of elementary carbon from the recycle gas stream was anticipated and was taken into account in the unit design; however, the problem is not limited to removal of carbon from the recycle gas. Repeated difficulty has been experienced in getting the carbon off the catalyst plates, out of the reactor, and to the lower end of the heat exchanger when carbon removal by a filter bag is to take place. Figures 20, 21, and 22 illustrate the carbon transport and removal problem. Figure 20 shows a clean catalyst plate ausembly. Figure 21 shows a catalyst plate assembly after the plate scraping mechanism failed. This permitted carbon buildup causing failure of the assembly drive mechanism. Figure 22 shows carbon buildup in the neck of the heat exchanger. Details of the carbon transport and removal problem and development efforts to find solutions to the problem are reported by Clark and Holmes in reference 5 . 
2. Carbon monoxide generation and leakage - During the design of the Bosch reactor, it was anticipated that when the unit was heated to the $1100^{\circ}$ to $1300^{\circ} \mathrm{F}$ operating temperature, a small amount of the recycle gas would leak into the cabin. The original estimate was a leakage of $2 \mathrm{cc} / \mathrm{min}$ of recycle gas with a carbon monoxide concentration of 20 percent. The catalytic oxidizer was sized accordingly and was designed to maintain a cabin carbon monoxide concentration of $10 \mathrm{ppm}$ with the oxidizer in the normal flow mode; however, during a 3-day, closed-door test of the IISS evidence was gained that the leakage rate of recycle gas into the cabin air approached $150 \mathrm{cc} / \mathrm{min}$. This leak rate overloaded the single catalytic oxidizer and caused the cabin total hydrocarbon and carbon monoxide concentrations to rise. A second catalytic oxidizer had to be ilased into operation and both units frequently had to be operated in the boost mode of flow. At one point in the test, the carbon monoxide concentration exceeded the red line value of $50 \mathrm{ppm}$. This occurred when the Bosch reactor was shyt down and opened for maintenance due to carbon blockage of the recycle gas flow through the heat exchanger.

\section{Water Electrolysis Unit}

Prior to the most recent integrated system test, a 4-day test completed in July 1967, operation of the electrolysis unit had been plagued with difficulty. The most severe problem encountered was the popping out of portions of the hypalon rubber spacers between cells in a stack. One of the hypalon spacers with imbedded coolant tubes is shown in figure 23. Very little force is required to pop out a flexible spacer. This was evidenced many times during stack assembly when normai compression required to seal the stack would pop or "squeeze" the $\because$ zcers out in a direction perpendicular to the compression force. When spacers pop out of the stack, li.quid containing the electrolyte can leak into the cell stack housing thus requiring shutdown of the assembly. A satisfactory fix may have been found to this problem as evidenced by the successful operation of the water electrolysis unit during the 4-day test in July. Fiber-glass strips were placed across the cell stacks to support the spacers. Unsupported spans were limited tc a distance of $I$ inch. A previous fix which utilized fiber-glass strip reinforcers placed along the edges of individual cells helped prevent spacer pop-out but may have contributed to another problem. The metal tubes carrying coolant to and from the cells corroded through at the interface with the fiber glass. As a result, nitroger from the module housing leaked into the coolant tubes and entered the entire system coolant circuit. In the current configuration, the coolant tubes are enclosed in a polyethylene shrink tubing and they do not contact the fiber-glass reinforcing strips. Additional testing is necessary to determine the long-term result of the fix.

Problems more specifically related to the electrochemical phase separation processes have also been encountered. Liquid carryover through the liquid-gas separation membranes has occurred to the extent that additional separators have been added to each of the product gas outlets. The prcblem has been more severe in the hydrogen side of the cells than in the oxygen side. The problem has not been completely defined to date; however, preliminary tests, using color-marked electrolyte and visual observation of the carryover, have indicated that the carryover is due to electrochemical phenomena rather than to capillary movement. Tests have also indicated that the carryover rate may be a function of cell 
temperature and electrolyte concentration, a higher carryover occurring with increasing temperature and decreasing electrolyte concentration.

An encouraging but unexplained event was the recent 4-day test during which the water electrolysis unit performed without difficulty. Spacers did not pop, liquid carryover did not occur, and cell voltages stabilized at approximately 2.0 volts. Additional analysis of the test data may uncover the reason for the success.

\section{Water Management Subsystem}

To this date, there have not been a sufficient number of controlled tests nor have they been of sufficient duration to produce conclusive results on the quality of the recovered water. Preliminary analysis of water samples from the 7-day test of February 1967 does indicate trends that will be investigated in more detail. Water recovered from humidity condensate and wash water appears to be of good quality based on chemical analysis. Electrical conductivity has been low ranging between 13 and 19 micromhos/centimeter. No odor or color has been detected. Water recovered from urine, however, has not been of equal quality. Electrical conductivity has ranged between 127 to $300 \mathrm{micromhos} /$ centimeter and has a detectable odor and color (turbidity). Traces of urea have been detected and total alkalinity has been relatively high ranging between 58 to 118 milligrams/liter reported as calcium carbonate. The system is very difficult to decontaminate biologically. After decontamination, it is also difficult to maintain in a clean condition. Biological analyses of the recovered water verify the presence of a biological contamination problem.

The technique of feeding waste water to the wicks has presented a problem. A single thermistor is placed vertically into the wick. The thermistor senses wick operating temperature which is a function of the combined termperature of the process airsteam and cooling effect of evaporation. As the wick dries, the temperature increases until it reaches a set point at which time a new batch of waste water is fed to the wick. Since the batch feed is based on temperature sensed by the thermistor, the accuracy of the signal from the thermistor is critical. Difficulty has been experienced in getting an accurate signal from the thermistor because small changes in its location with respect to wick and wick spacer materials produce large differences in sensed temperatures. If the thermistor senses a temperature higher than the overall representative wick temperature, batching is too frequent and flooding results. If the thermistor senses a temperature lower than the overall representative wick temperature, batching is not frequent enough and the wick dries out and causes changes in the chemical makeup of the product water.

\section{Trace Contamination}

Some results of contamination studies as related to operation of the Bosch reactor have been discussed in a previous section of the paper. As was stated, high carbon monoxide and significant total hydrocarbon levels concentrations were detected. However, studies made during the 7-day test of February 1967 as 
reported by Pearson and Johnson (ref. 7) indicate a clean atmosphere when operating with the Sabatier reactor. Table I (ref. 7 ) is a table of contaminants looked for and found by online monitoring equipment. Note the low, 0 to $6 \mathrm{ppm}$, carbon monoxide and low, 2.5 to $15 \mathrm{ppm}$, total hydrocarbon concentrations.

Other trace contaminant identification work using multistaged cold traps for sampling and gas chromatography and mass spectrometry for analysis is being conducted but results are still preliminary. A typical preliminary analysis of samples from the 3-day test of June 1967 has identified 34 trace compounds making up a combined total of 18 milligrams of sample. 
REFERENCES

1. Woods, R. W.; and Erlanson, E. P.: Study of Thermal Integration of Electric Power and Life support Systems for Manned Space Stations. NASA Doc. No. 66SD423I.

2. Murray, R. W.; Mangialard, J.; and Cooper, I.: Thermally Integrated Iife Support Systems. Amer. Inst. of Aero. and Astro., 3, 274-285, 1965.

3. McKhann, G. G.: Preliminary Design of a Pu-238 Isotope Brayton Cycle Power System for MORL. Volume IV. Douglas Aircraft Company, Inc., No. SM-48837, 1965.

4. Anon.: Environmental Control and Life Support System Study. Volume 4. Final Report NASA Contract NAS9-1498, 1964.

5. Clark, L. G.; and Holmes, R. F.: Carbon Dioxide Reduction Unit Operation with Bosch Reduction. Langley Working Paper, LWP-387, 1967.

6. Armstrong, R. C.: Iife Support Systems for Space Flights of Extended Time Periods. NASA CR-614, 1966.

7. Pearson, A. 0.; and Johnson, R. W.: Seven-Day, Closed-Door Test of Iangley Integrated Iife Support System. Iangley Working Paper LWP-378, 1967.

8. Pearson, A. 0.; and North, B. F.: 24-Hour Functional Evaluation of the Langley Integrated Life Support System. Langley Working Paper LWP-393, 1967 .

9. Langley Research Center Staff: Selected Papers on Environmental and Attitude Control of Manned Spacecraft. NASA TM X-1325, 1966.

10. Anon.: Reanalysis of ISS Thermal Control System. GDC No. 64-26241, NASA Contract NASI-2934, 1965.

11. Drake, G. L.: Life Support Integration Summary for Space Flights of One Year Duration. GDC No. 64-26216, NASA Contract NAS1-2934, 1963. 
TABLE I. - ILSS ATMOSPHERIC ANAT YSES, SUMMARY OF AVERAGED VALUES WITH HICHS AND LOWS

\begin{tabular}{|c|c|c|c|c|c|c|c|c|c|c|c|}
\hline \multirow{2}{*}{ Analysis Date } & \multirow{2}{*}{$\begin{array}{l}\text { Units } \\
\text { By Vol. }\end{array}$} & \multicolumn{8}{|c|}{ Averaged values } & \multicolumn{2}{|c|}{7 day } \\
\hline & & $\begin{array}{l}\text { Jan. } \\
31\end{array}$ & $\begin{array}{c}\text { Feb. } \\
1\end{array}$ & $\begin{array}{l}\text { Feb. } \\
2\end{array}$ & $\begin{array}{l}\text { Feb. } \\
3\end{array}$ & $\underset{4}{\mathrm{Feb}}$ & $\begin{array}{l}\text { Feb. } \\
5\end{array}$ & $\begin{array}{l}\text { Feb. } \\
6\end{array}$ & $\begin{array}{l}\text { Feb. } \\
7\end{array}$ & Low & High \\
\hline $\begin{array}{l}\text { Process G. C. } \\
\mathrm{O}_{2} \\
\mathrm{~N}_{2} \\
\mathrm{CO}_{2} \\
\mathrm{CO}^{2} \\
\mathrm{H}_{2} \\
\mathrm{CH}_{4} \\
\mathrm{H}_{2} \mathrm{O}\end{array}$ & $(\%)$ & $\begin{array}{l}22 \\
78 \\
0.79 \\
0 \\
0 \\
0 \\
1.7\end{array}$ & $\begin{array}{l}22 \\
76 \\
0.80 \\
0 \\
0 \\
0 \\
2.0\end{array}$ & $\begin{array}{l}21 \\
74 \\
0.78 \\
0 \\
0 \\
0 \\
2.0\end{array}$ & $\begin{array}{l}21 \\
74 \\
0.73 \\
0 \\
0 \\
0 \\
1.9\end{array}$ & \begin{tabular}{|l|}
21 \\
74 \\
0.75 \\
0 \\
0 \\
0 \\
1.9
\end{tabular} & $\begin{array}{l}21 \\
75 \\
0.75 \\
0 \\
0 \\
0 \\
1.7\end{array}$ & $\begin{array}{l}21 \\
76 \\
0.74 \\
0 \\
0 \\
0 \\
1.8\end{array}$ & \begin{tabular}{|l|}
21 \\
77 \\
0.78 \\
0 \\
0 \\
0 \\
1.9
\end{tabular} & $\begin{array}{l}21 \\
74 \\
0.60 \\
0 \\
0 \\
0 \\
1.4\end{array}$ & $\begin{array}{l}23 \\
80 \\
1.00 \\
0 \\
0 \\
0 \\
2.5\end{array}$ \\
\hline Pressure & (torr) & 766 & 764 & 759 & 766 & 761 & 757 & 758 & 753 & T50 & 769 \\
\hline $\begin{array}{l}\text { Wet Chem. } \\
\mathrm{NH}_{3} \\
\mathrm{SO}_{2} \\
\mathrm{H}_{2} \mathrm{~S} \\
\mathrm{No} \\
\mathrm{NO}_{2} \\
\text { Mercaptan* }\end{array}$ & (ppm) & $\begin{array}{l}0 \\
0 \\
0 \\
0 \\
0 \\
0\end{array}$ & $\mid \begin{array}{r}0 \\
<1 \\
0 \\
0 \\
0 \\
0\end{array}$ & $\begin{array}{l}0 \\
0 \\
0 \\
0 \\
0 \\
0\end{array}$ & $\begin{array}{l}0 \\
0 \\
0 \\
0 \\
0 \\
0\end{array}$ & $\begin{array}{l}0 \\
0 \\
0 \\
0 \\
0.1 \\
0\end{array}$ & $\begin{array}{l}0 \\
0 \\
0 \\
0 \\
0 \\
0\end{array}$ & $\begin{array}{l}0 \\
0.3 \\
0 \\
0 \\
0 \\
0\end{array}$ & $\begin{array}{l}0 \\
0 \\
0 \\
0.1 \\
0 \\
0\end{array}$ & $\begin{array}{l}0 \\
0 \\
0 \\
0 \\
0 \\
0\end{array}$ & $\mid \begin{array}{l}0 \\
<1 \\
0 \\
0.1 \\
0.1 \\
0\end{array}$ \\
\hline $\begin{array}{l}\text { Trace G. C. } \\
\text { Acetone } \\
\text { Alcohol** } \\
\text { Benzene } \\
\text { Trichloroethylene } \\
\text { CO } \\
\mathrm{CH}_{4} \\
\mathrm{H}_{2}\end{array}$ & (ppm) & $\begin{array}{l}0 \\
0 \\
0 \\
0 \\
1 \\
0 \\
7\end{array}$ & $\begin{array}{l}0 \\
4 \\
0 \\
0 \\
1.5 \\
1.5 \\
200\end{array}$ & $\begin{array}{l}0 \\
5 \\
0 \\
0 \\
1.5 \\
1 \\
58\end{array}$ & $\begin{array}{c}0 \\
<0.5 \\
0 \\
0 \\
0.3 \\
1 \\
52\end{array}$ & $\mid \begin{array}{c}<0.1 \\
<1 \\
0 \\
0 \\
<0.5 \\
1 \\
52\end{array}$ & $\mid \begin{array}{l}<0.1 \\
1 \\
0 \\
0 \\
<0.5 \\
1.5 \\
48\end{array}$ & $\begin{array}{l}0 \\
3.5 \\
0 \\
0 \\
1.2 \\
4 \\
59\end{array}$ & $\begin{array}{l}0 \\
<1 \\
0 \\
0 \\
<0.5 \\
1 \\
50\end{array}$ & $\begin{array}{l}0 \\
0 \\
0 \\
0 \\
0 \\
0 \\
7\end{array}$ & $\begin{array}{c}<0.1 \\
10 \\
0 \\
0 \\
2 \\
12 \\
160\end{array}$ \\
\hline $\begin{array}{l}\text { Total } \\
\text { Hydrocarbons**** }\end{array}$ & (ppm) & 3 & 4 & 6 & 5 & 5 & 6 & 6 & 6 & 2.5 & 15 \\
\hline Co Analyzer & (ppm) & 4 & 2 & 1 & $\ddot{i}_{1} 5$ & 2.5 & 1.5 & 1.8 & 2 & 0 & 6 \\
\hline
\end{tabular}

*As methyl mercaptan equivalent.

**As methyl alcohol equivalent.

***As methane equivalent. 
LIFE SUPPORT SYSTEM TEST BED INTERIOR

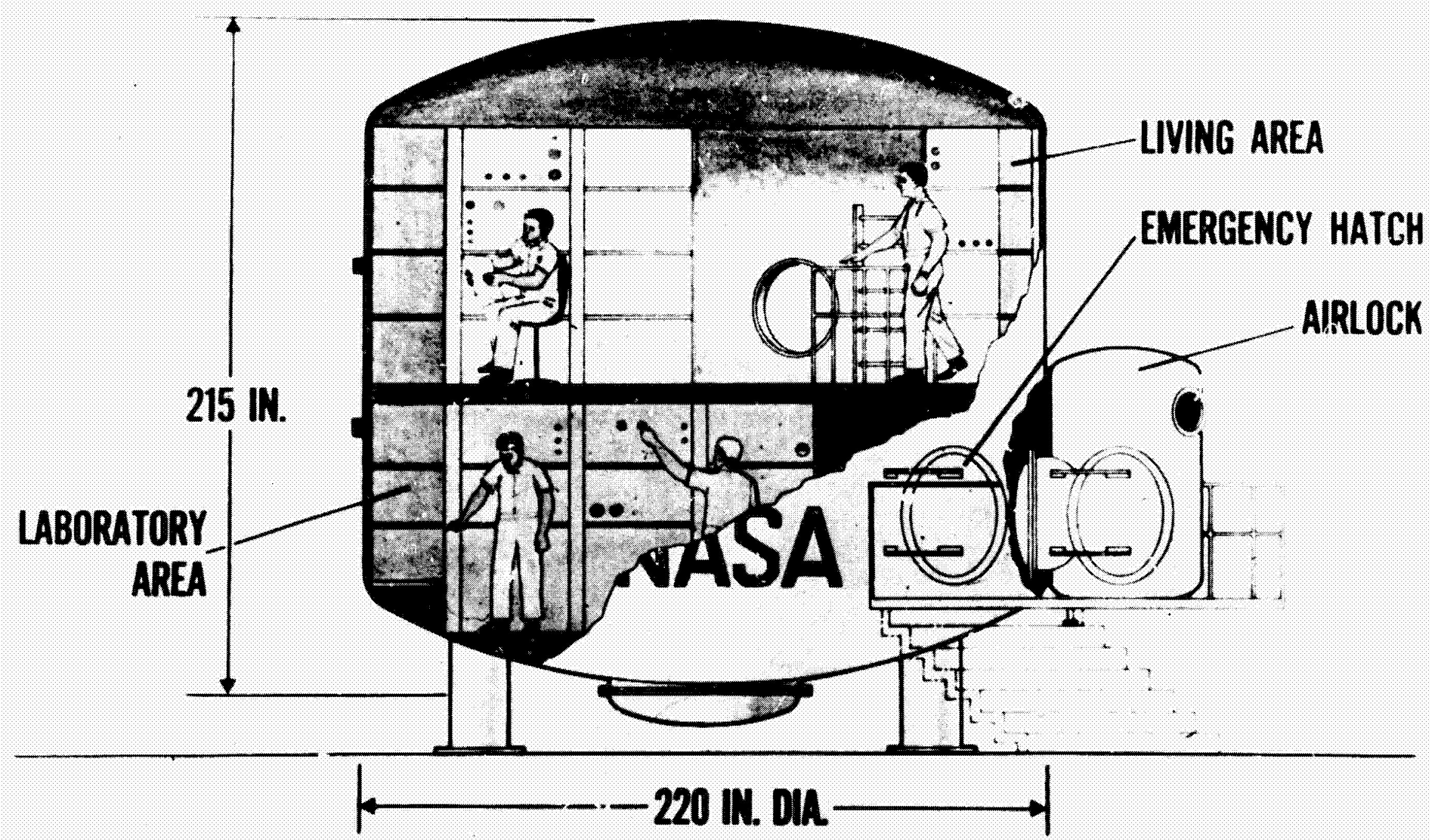

Figure 1.- Artist's concept of the ILS3. 


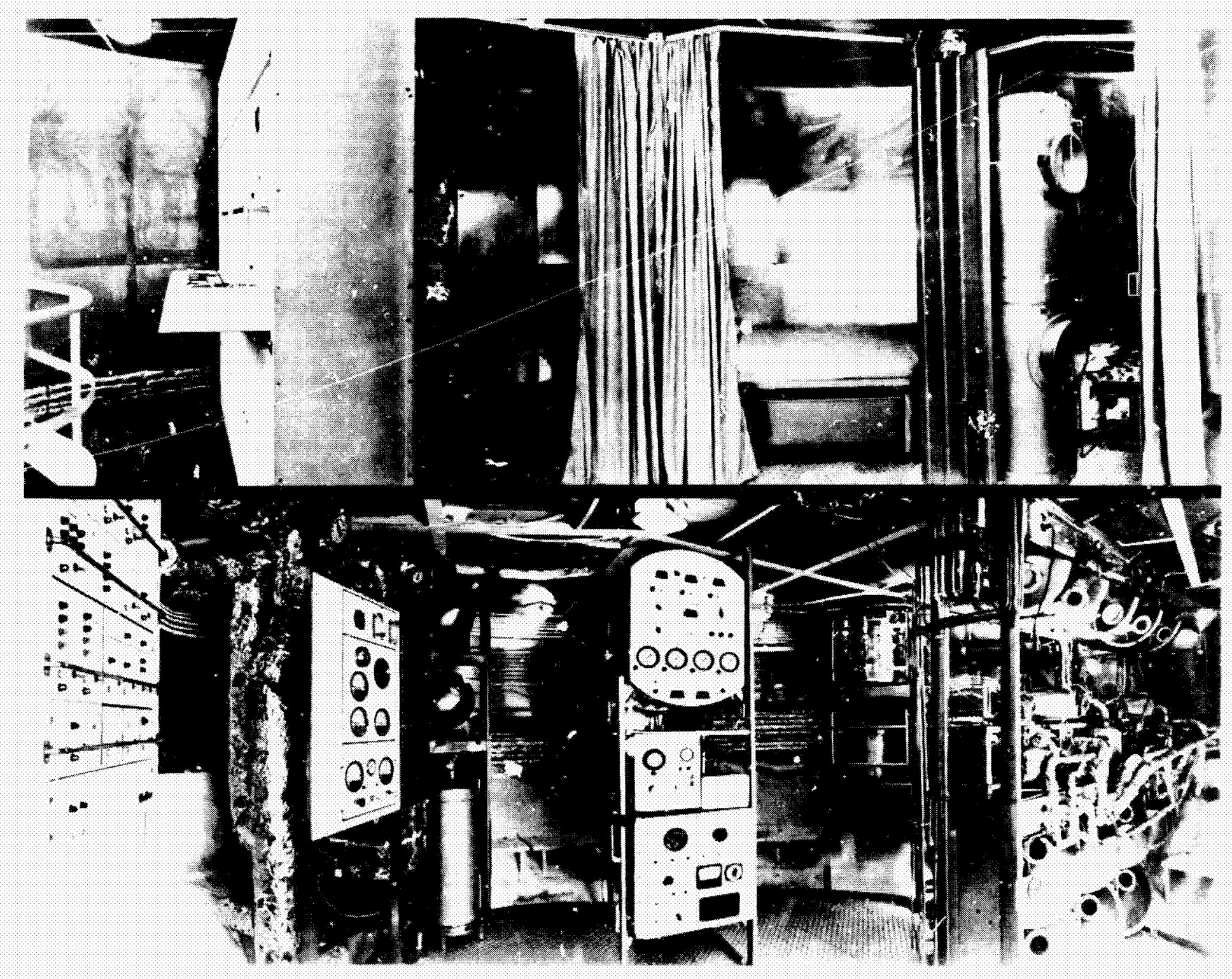

Figure 2.- Composite photograph of the EC/LS system. 


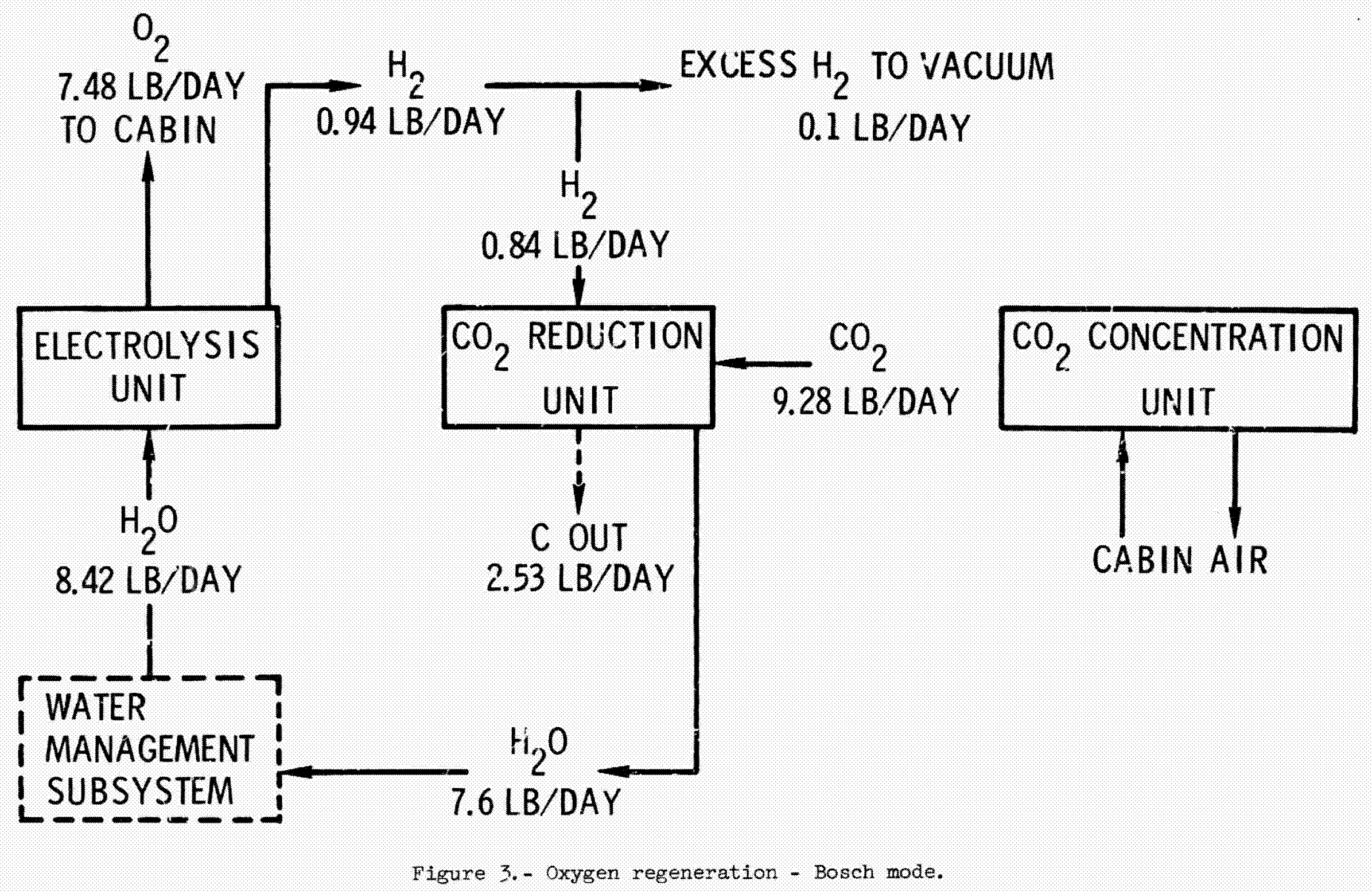




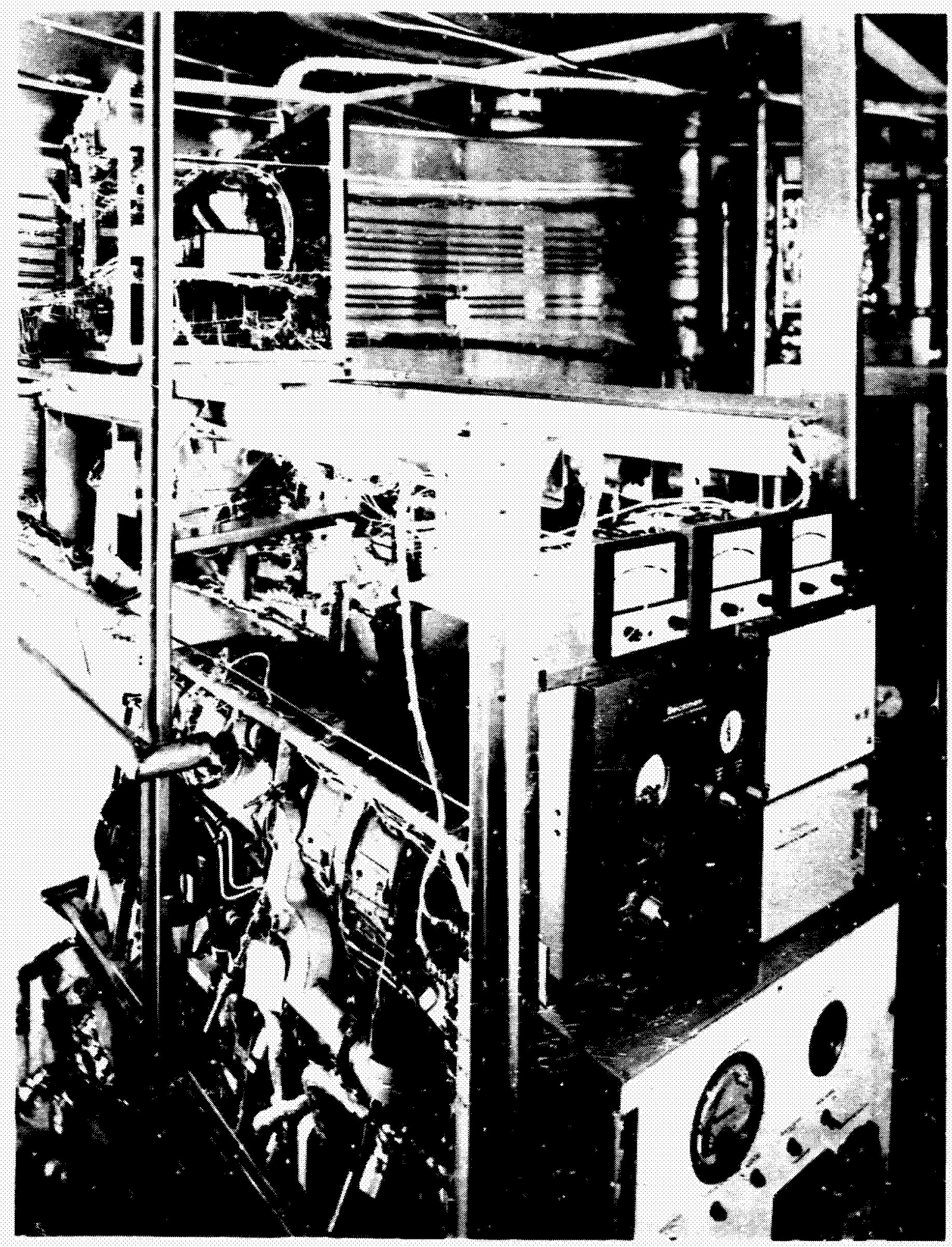

Figure 4.- Carbon dioxide concentrator. 


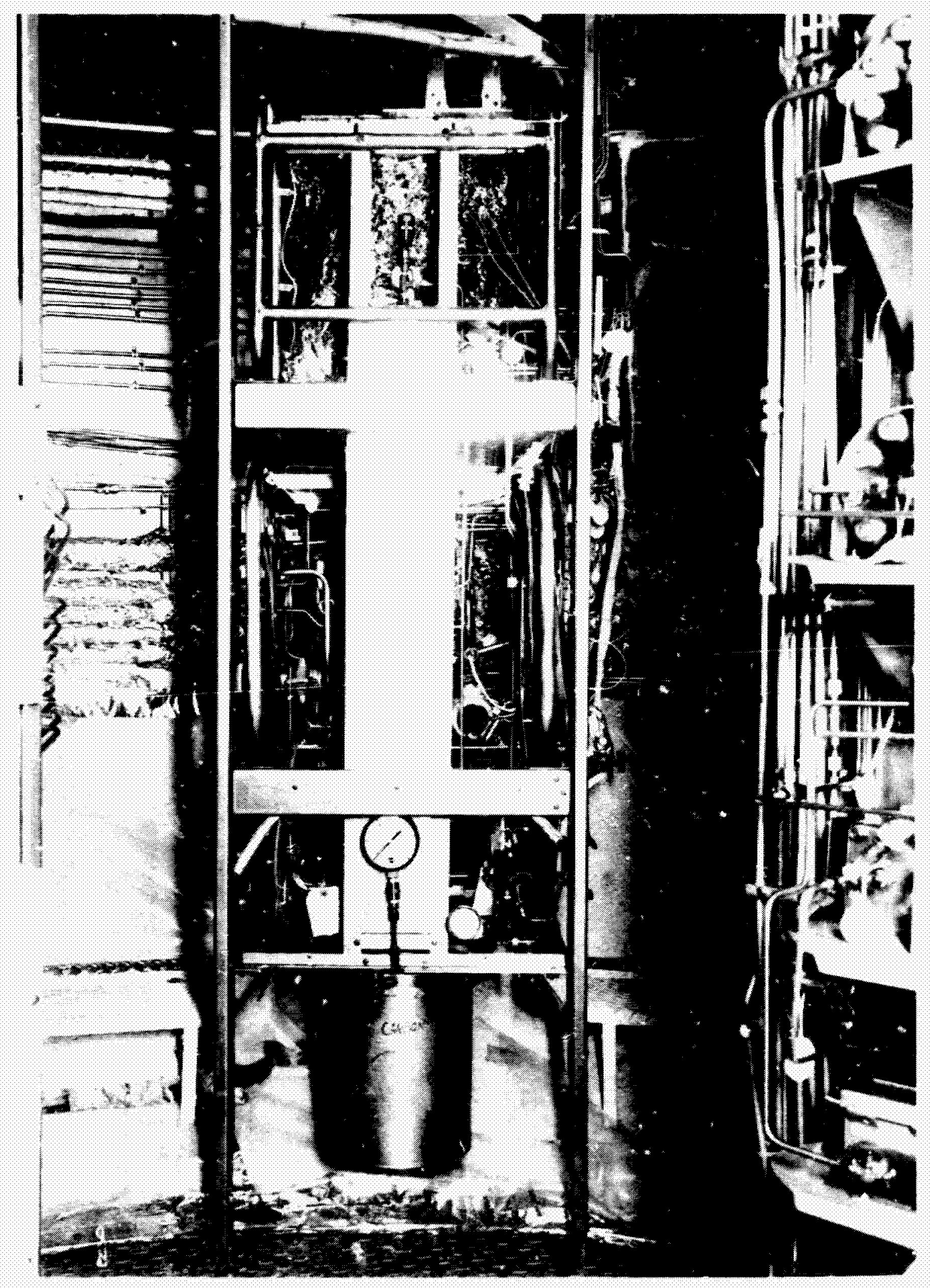

Figure 5.- Carbon dioxide reduction untt. 


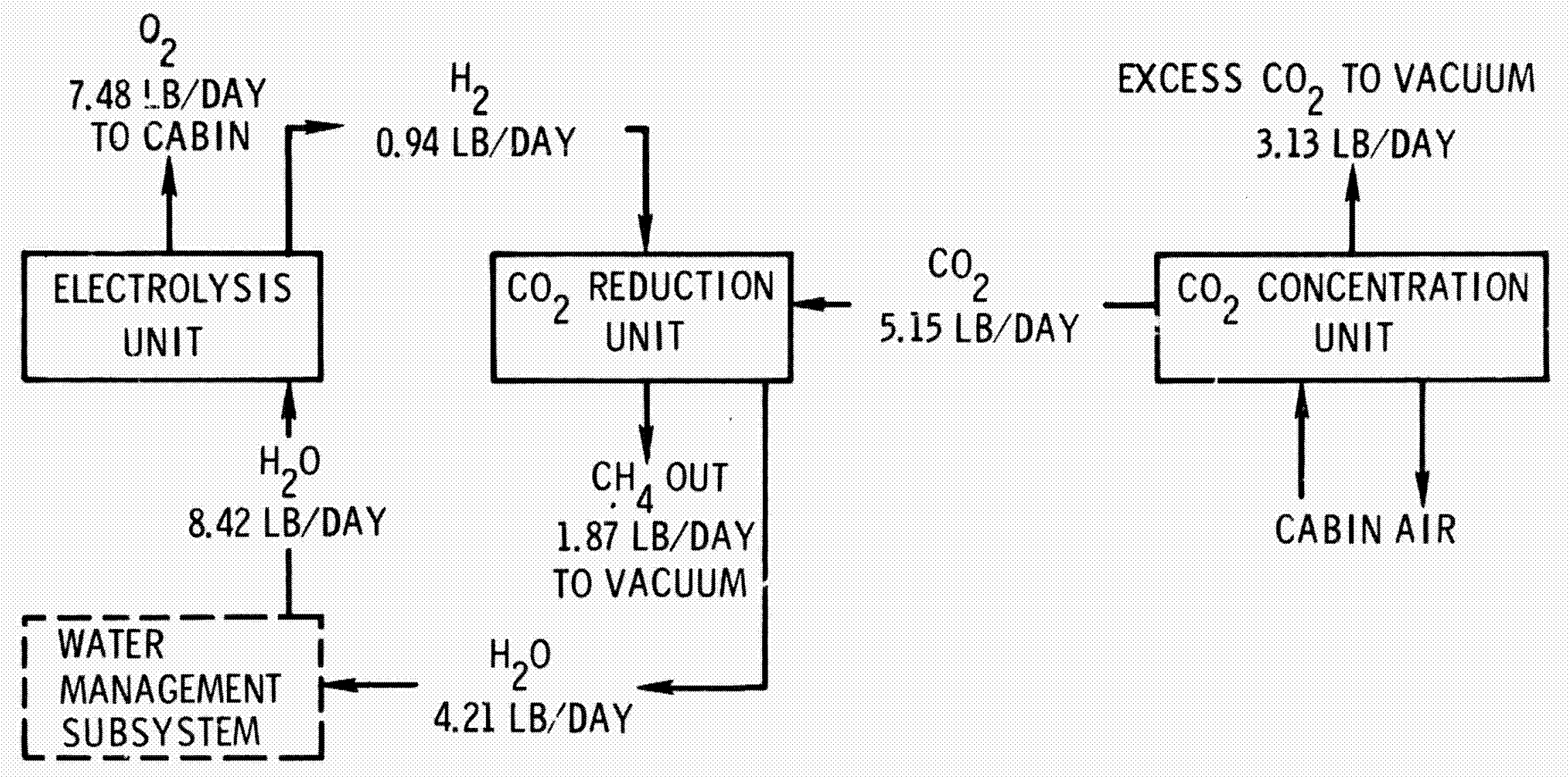

Figure 6.- Oxygen regneration - Sabatier mode. 


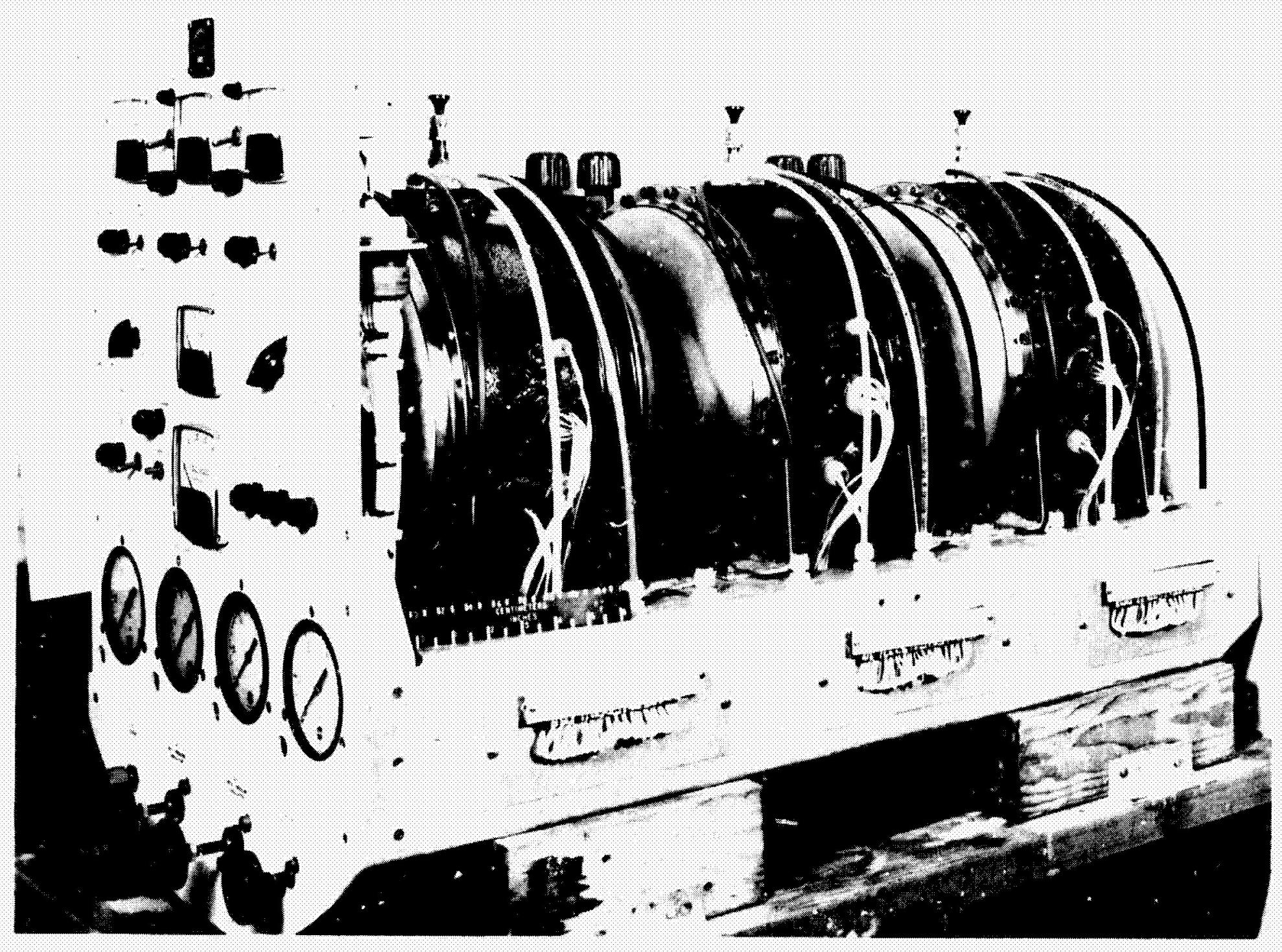

Figure 7.- Water electrolysis unit. 


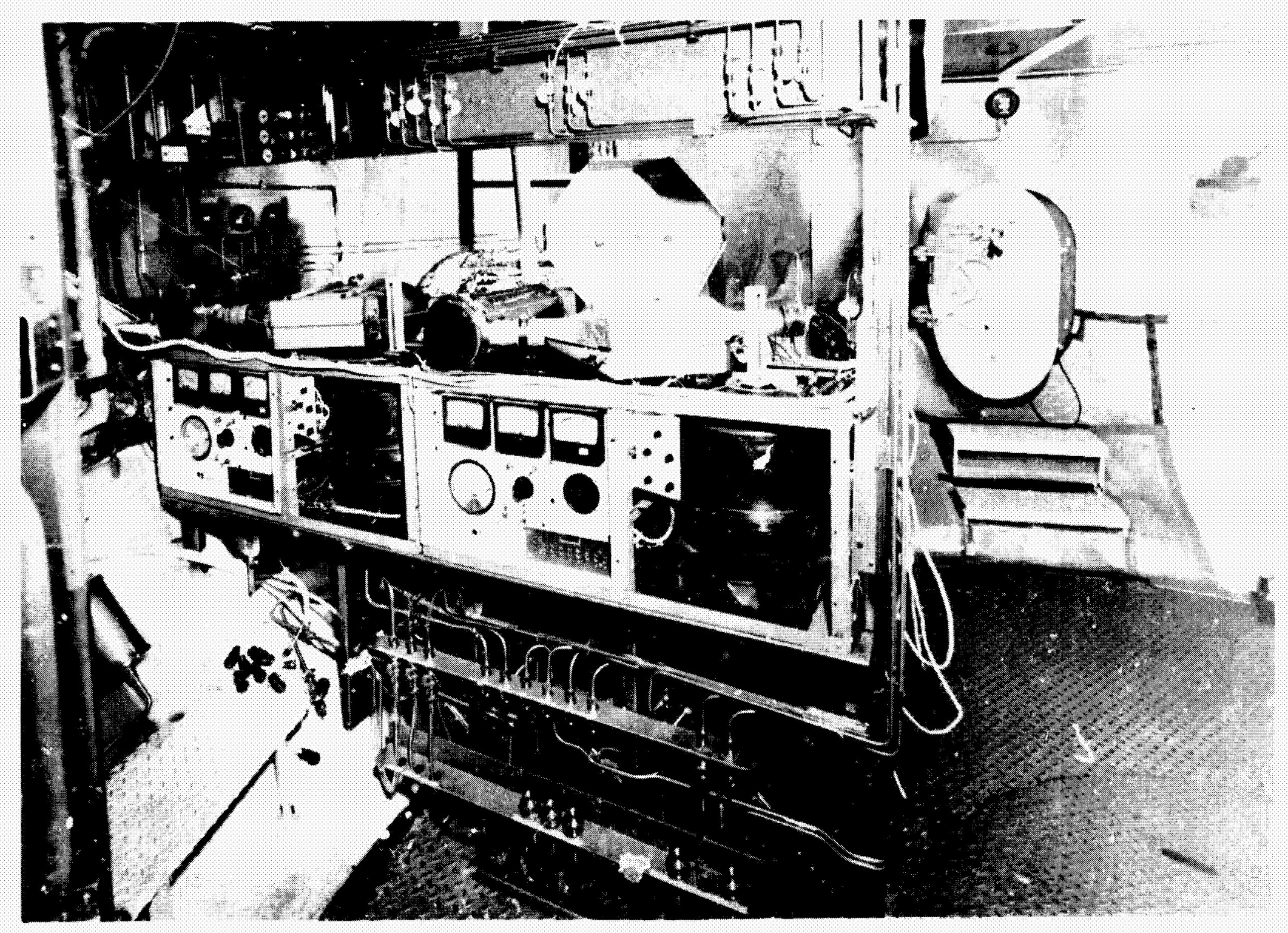

Figure 8,- Water management subsystem. 


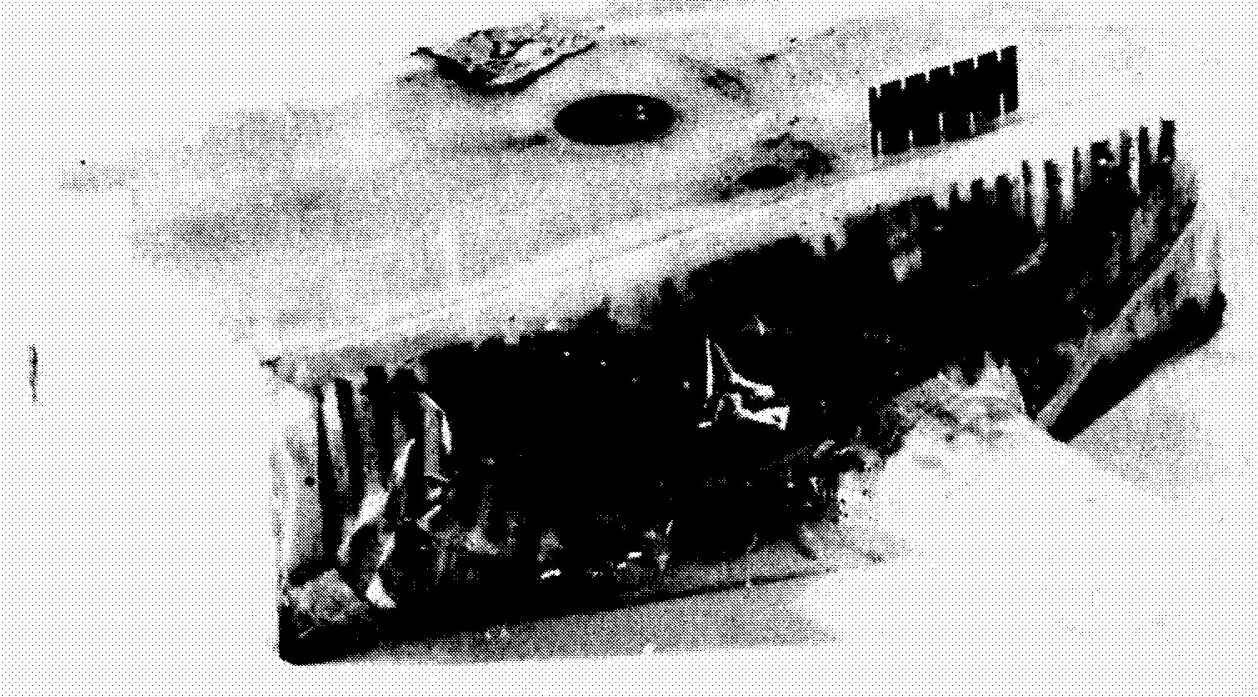

Figure 9.- Wick-type evaporation unit. 


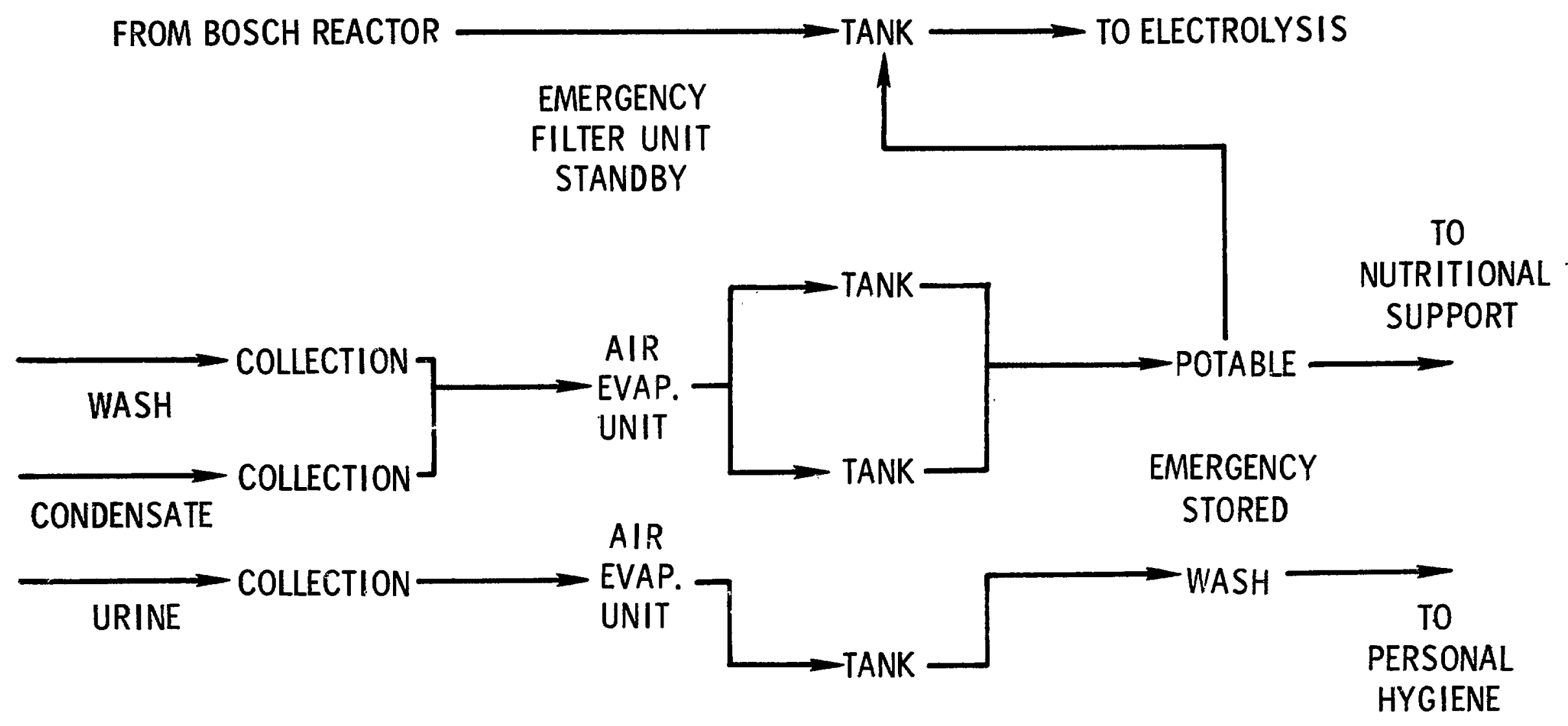

Figure 10.- Normal processing mode. 


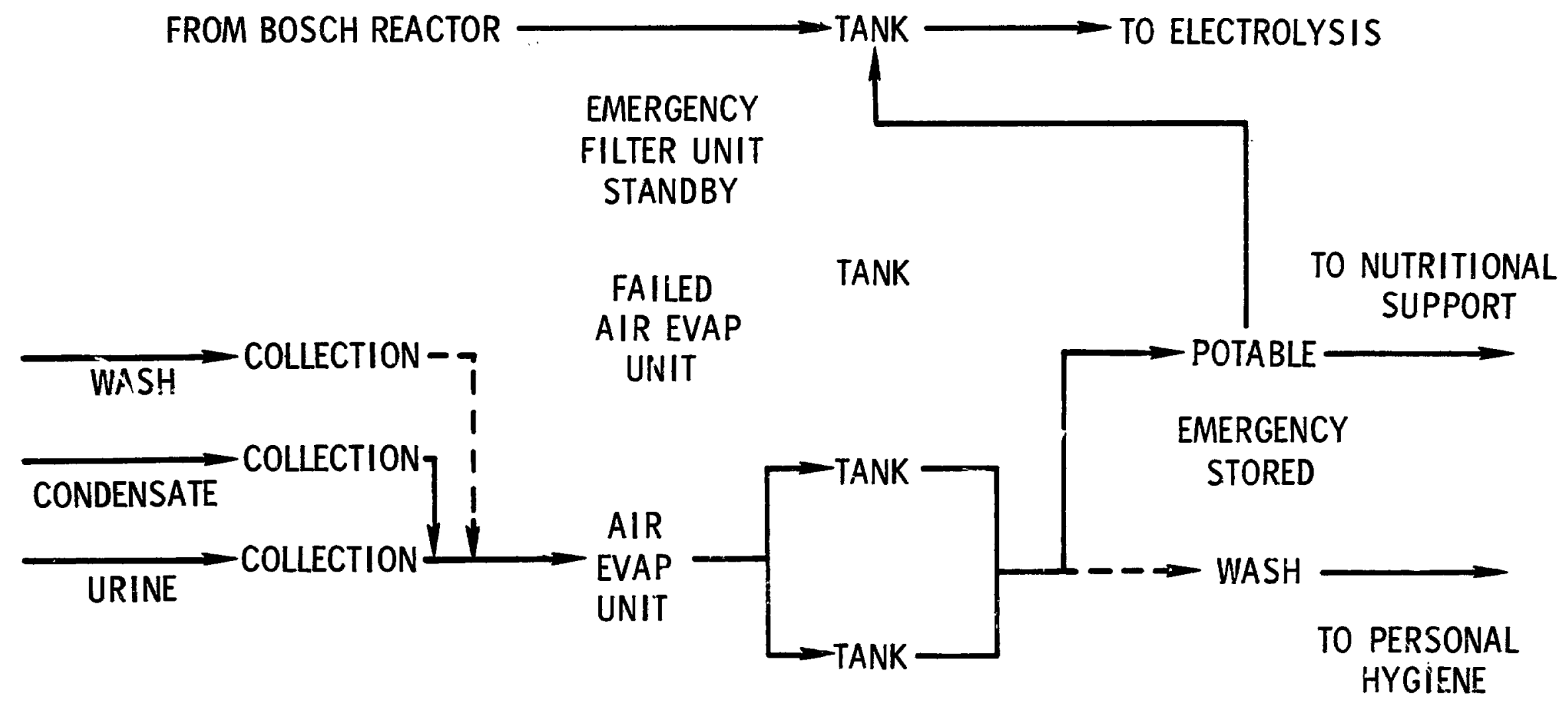

Figure 11. - Minimum continuous mode. 


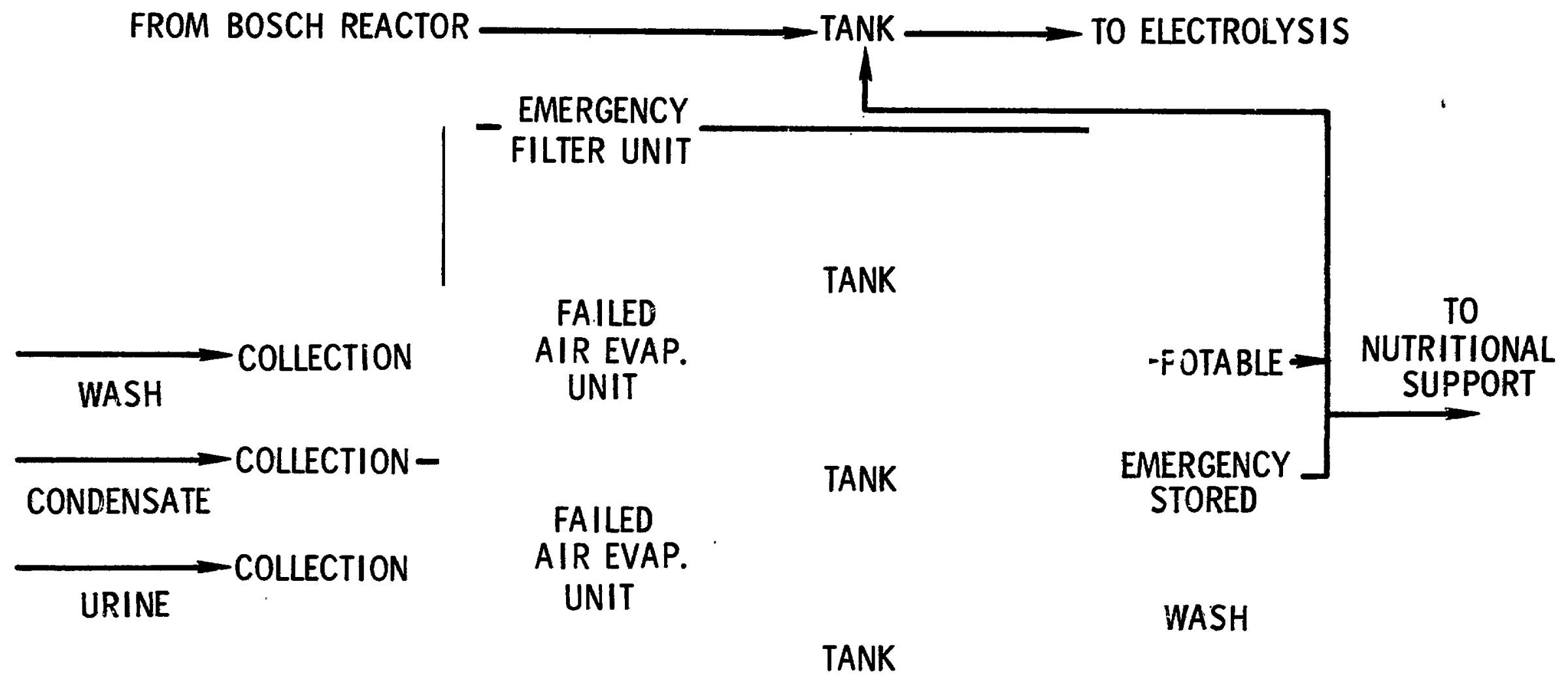

Figure 12. - Emergency mode. 


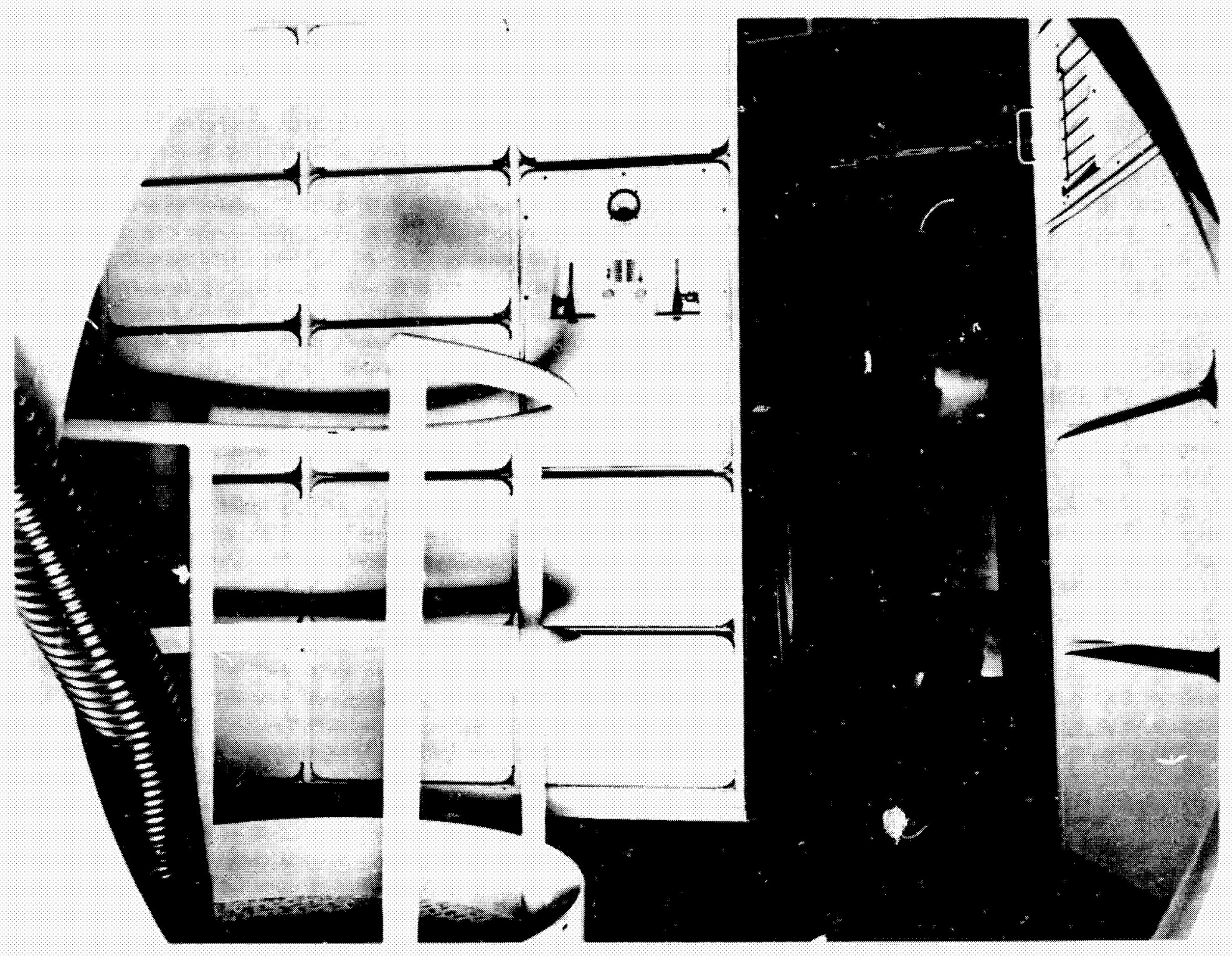

Figure 13.- Nutritional support console. 


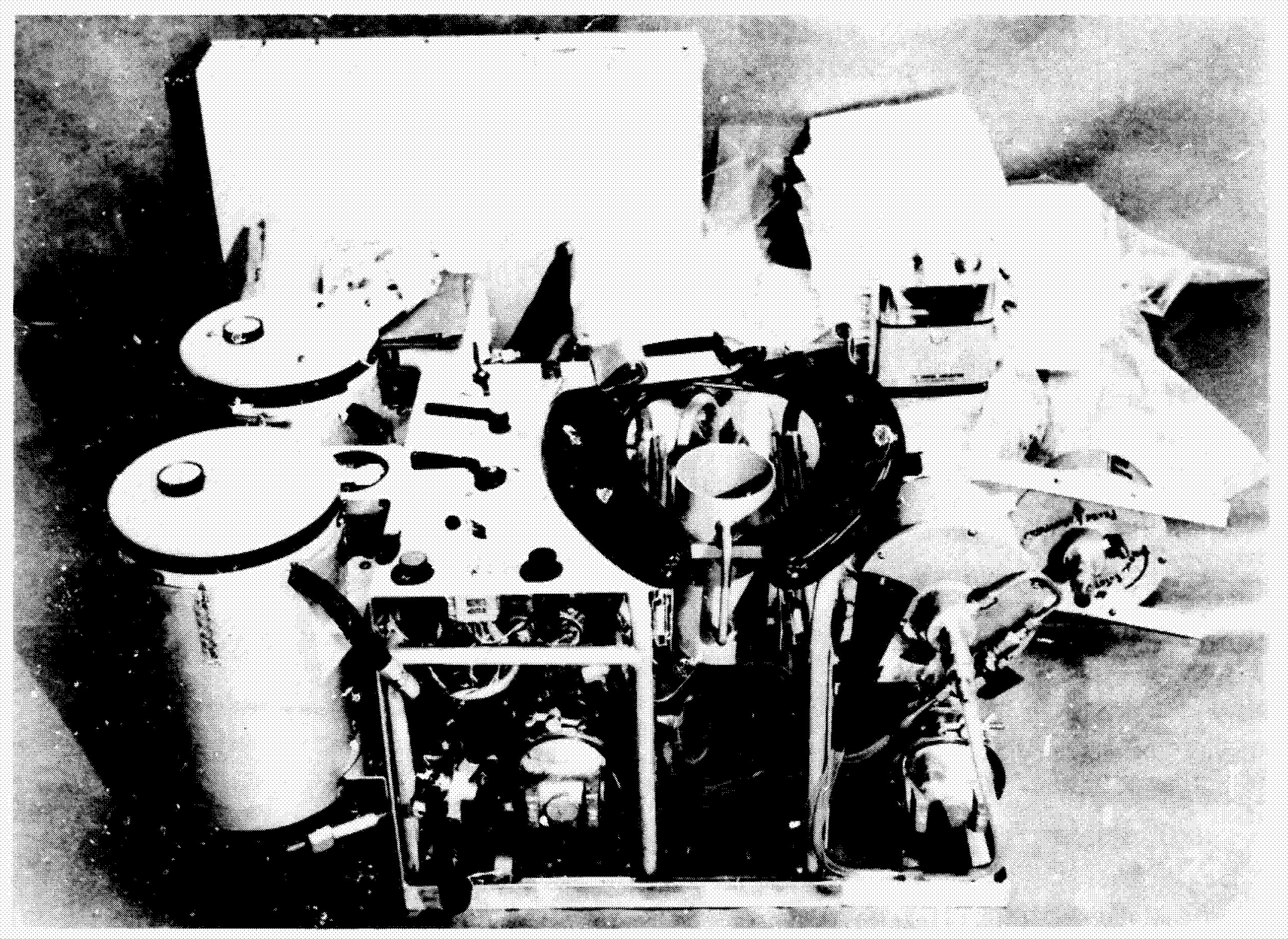

Figure 14.- Waste management unit. 


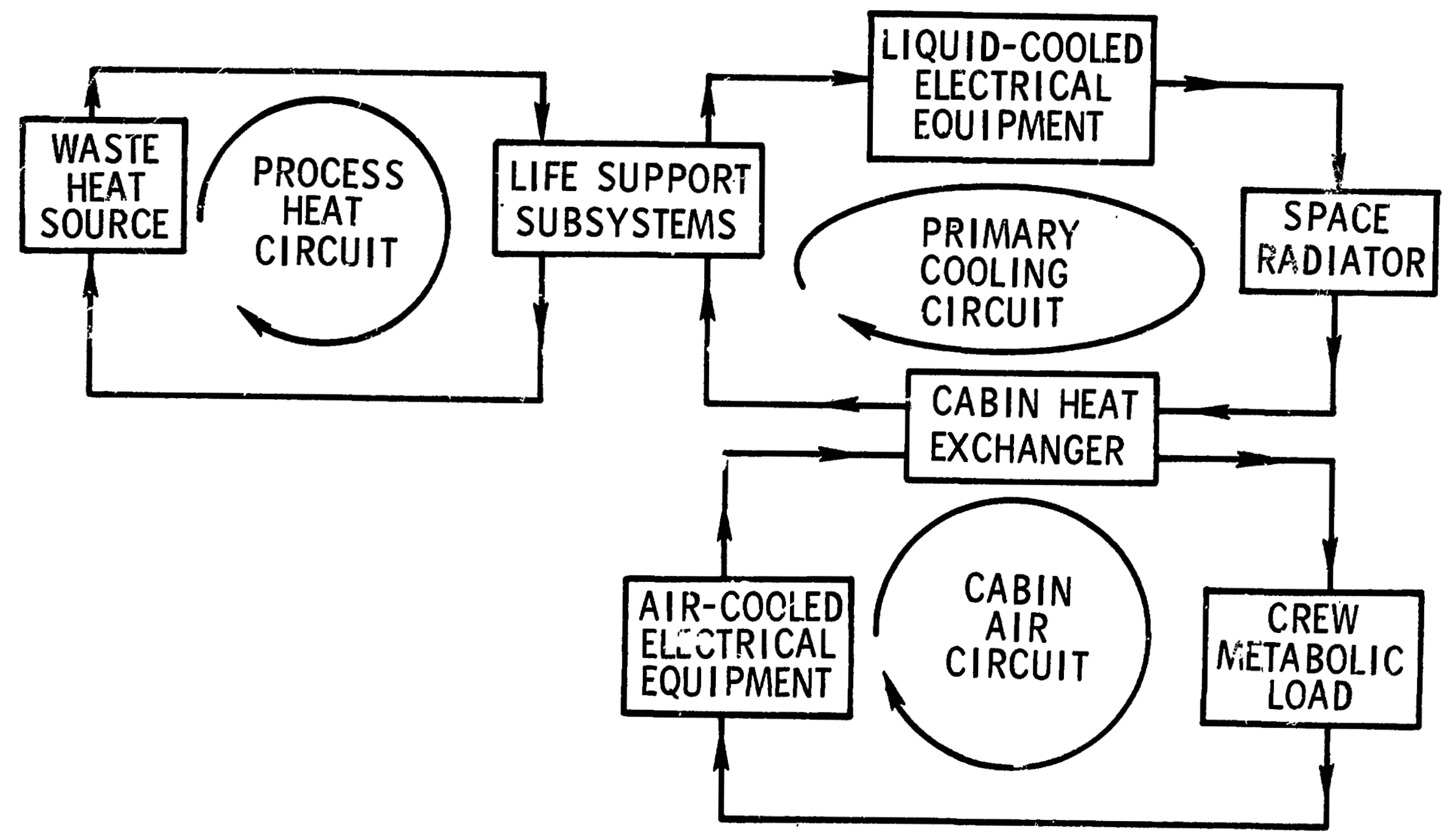

Figure 15. - Integration of the thermal control circuits. 


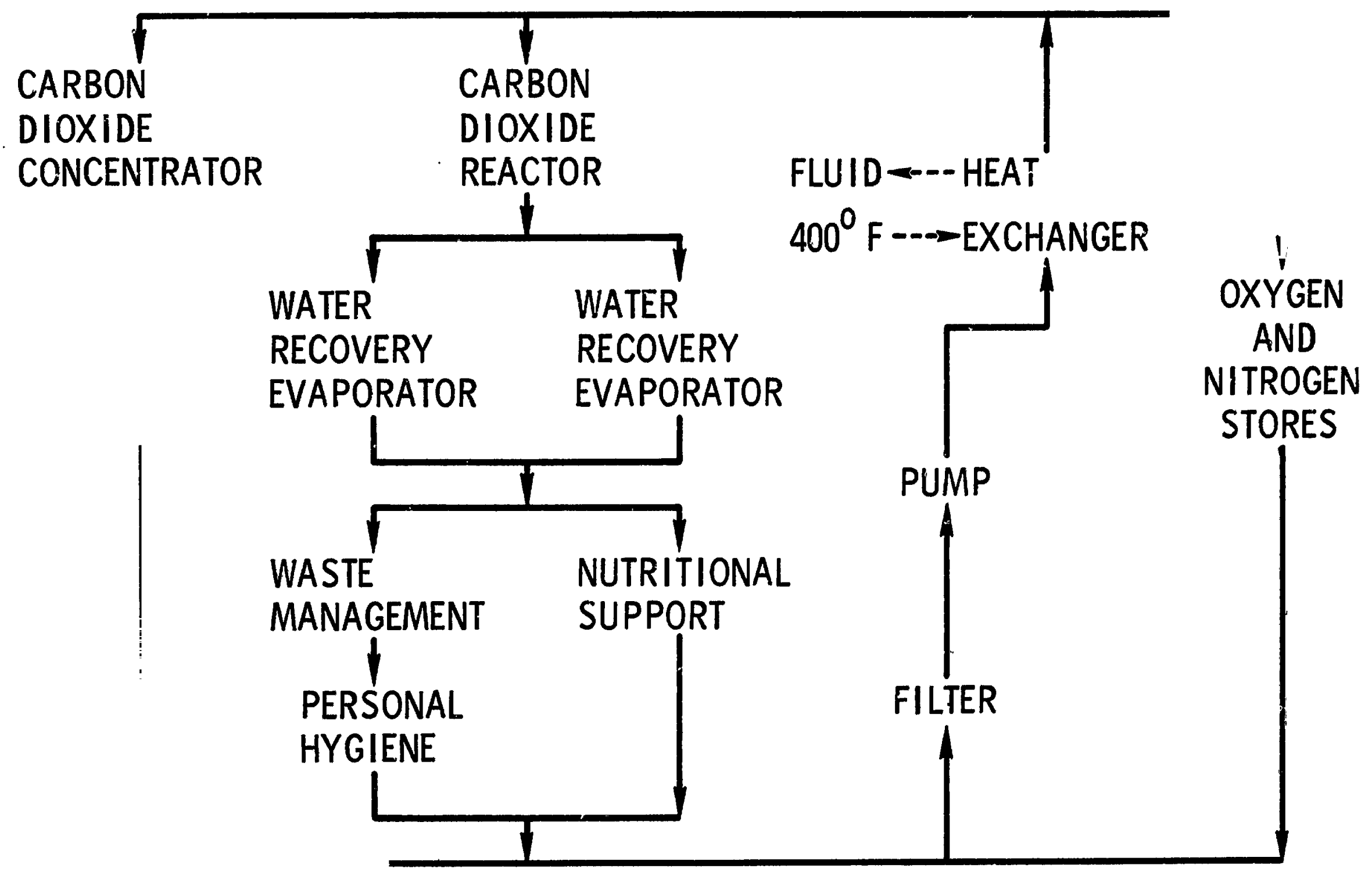

Figure 16.- Process heat clrcuit. 


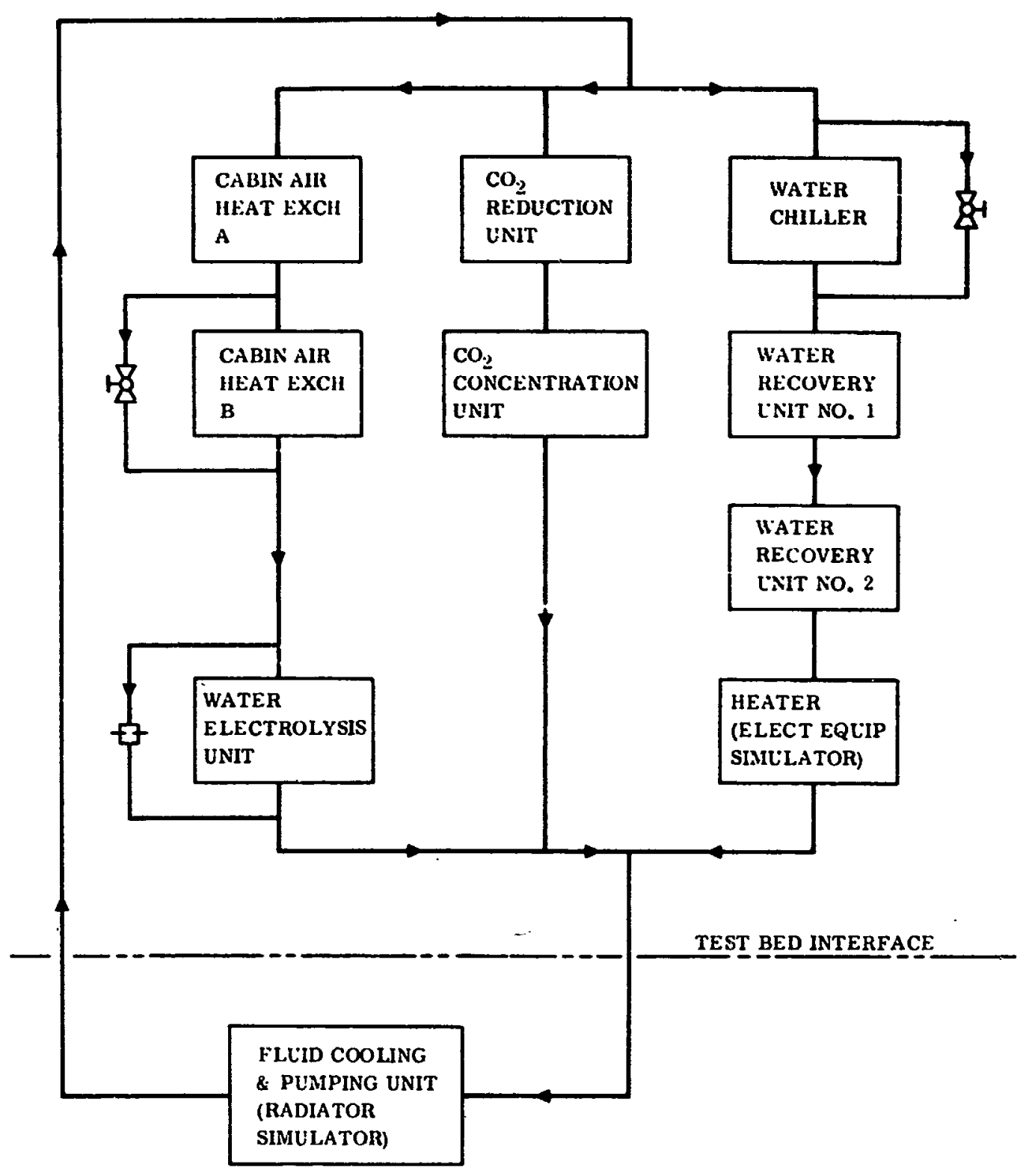

Figure 17.- Primary coolant circuit. 


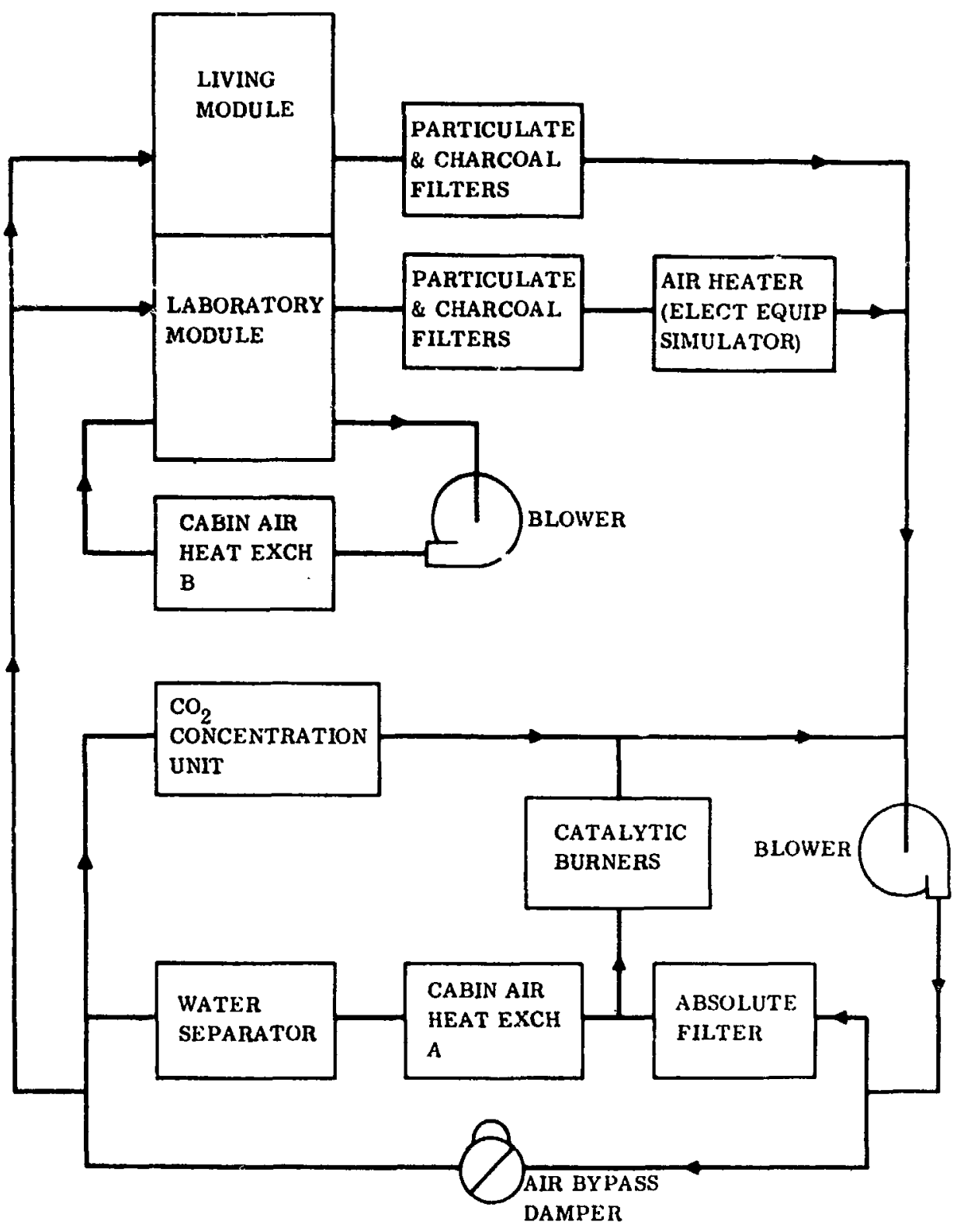

Figure 18.- Cabin air circuit. 


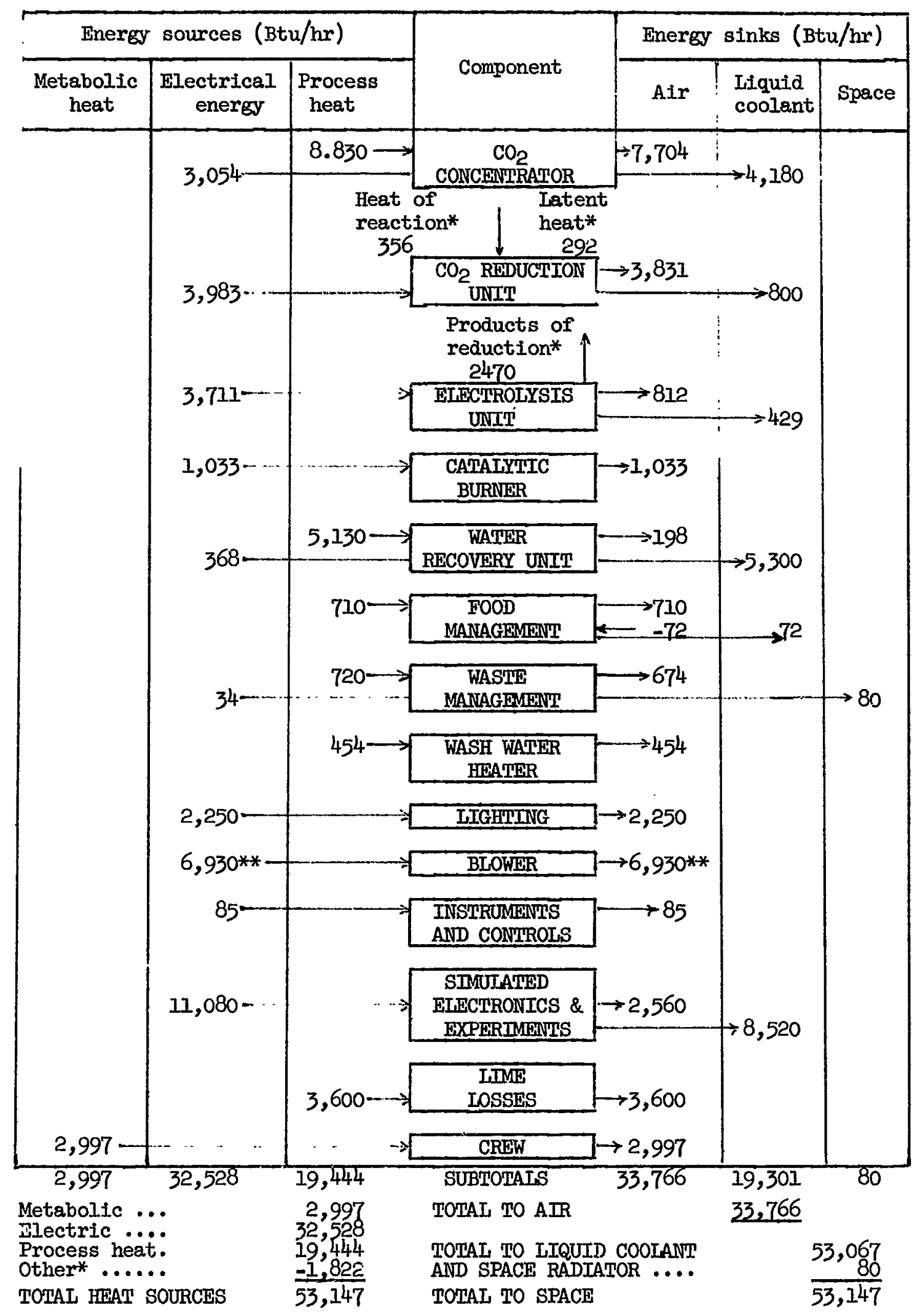

**Includes suit blower load of $1,705 \mathrm{Btu} / \mathrm{hr}$.

Figure 19. - Heat load summary, maximum. 


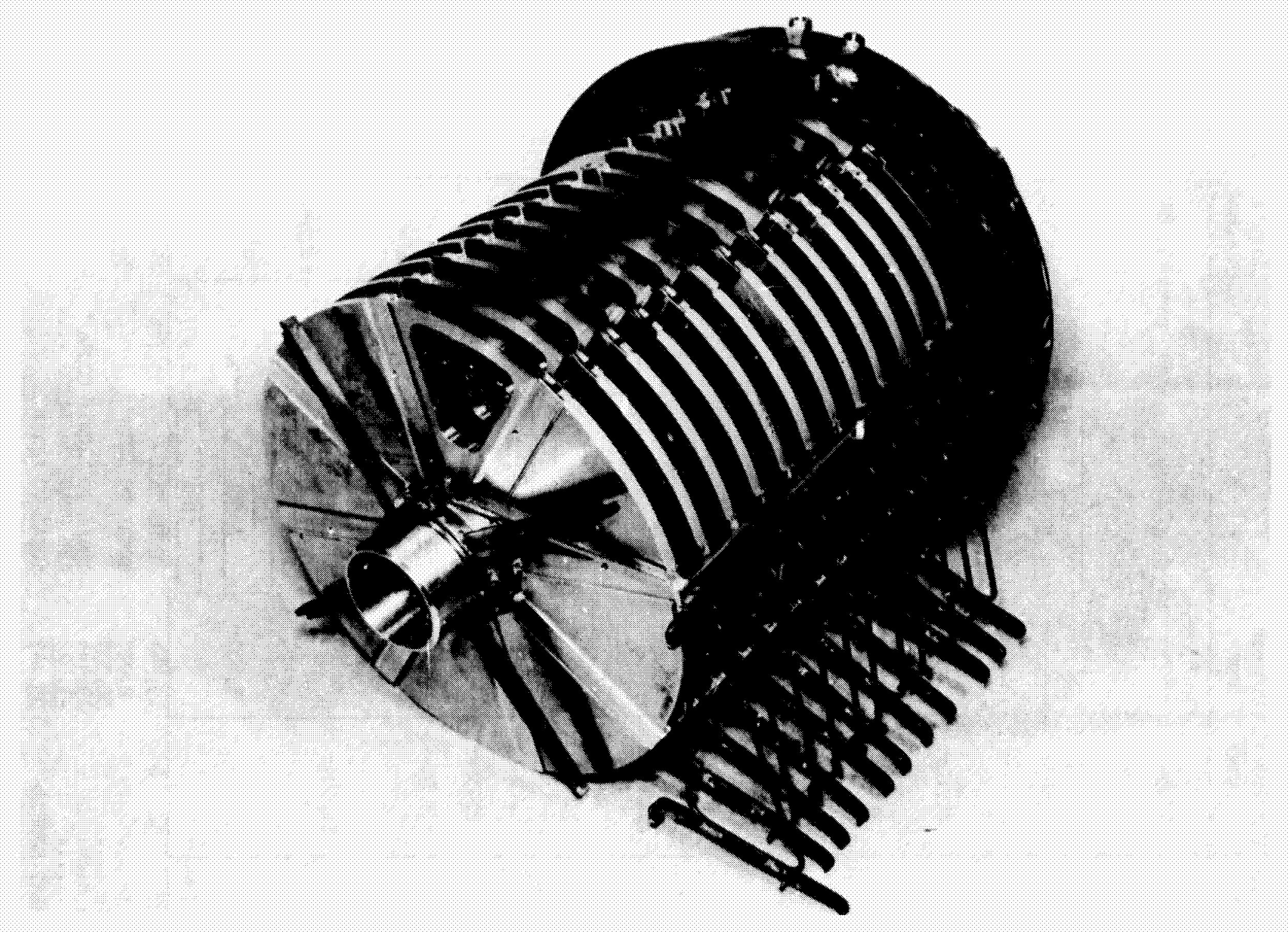

Figure 20.- Catalyst plate assembly. 


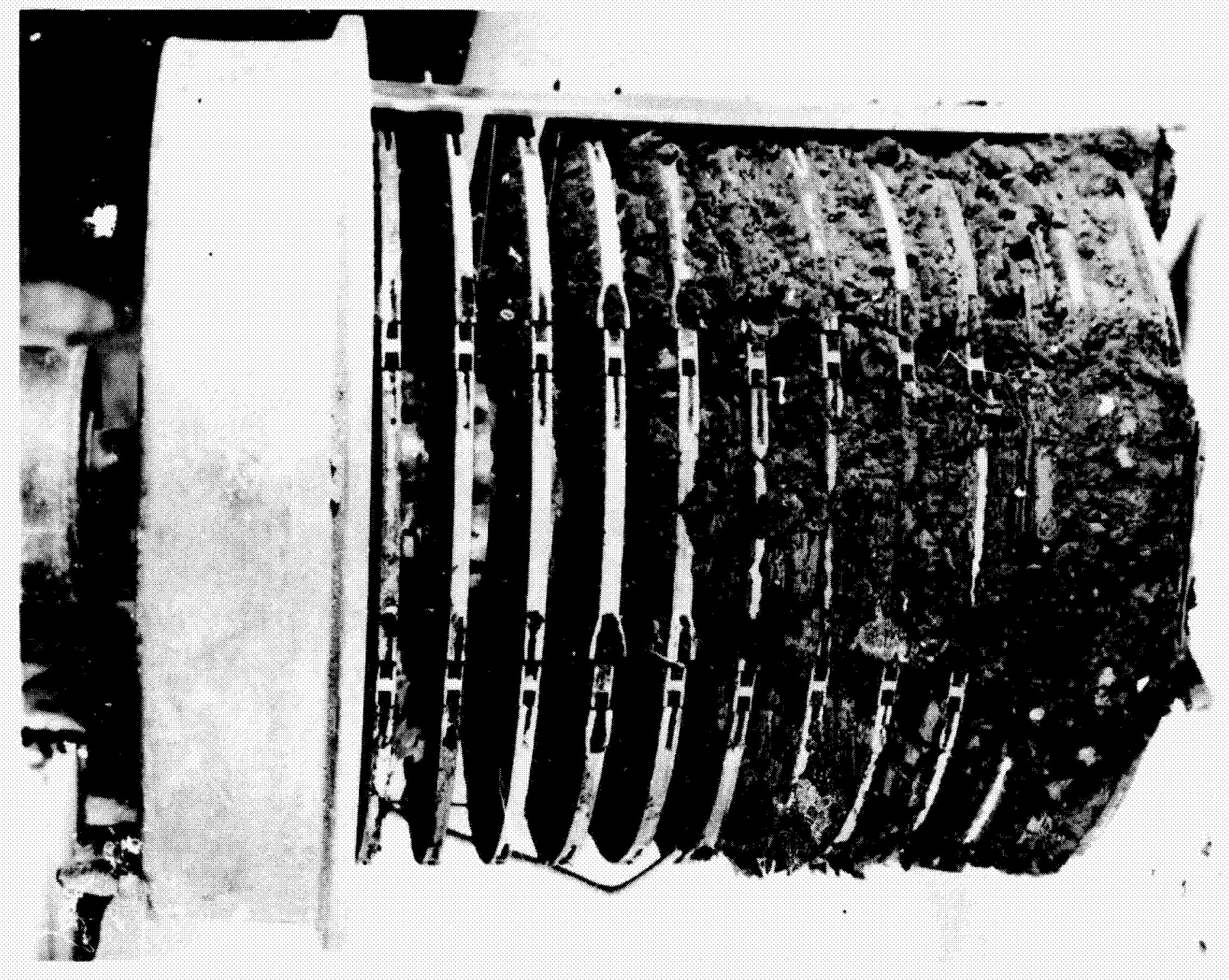

Figure 21.- Carbon build-up on plates. 


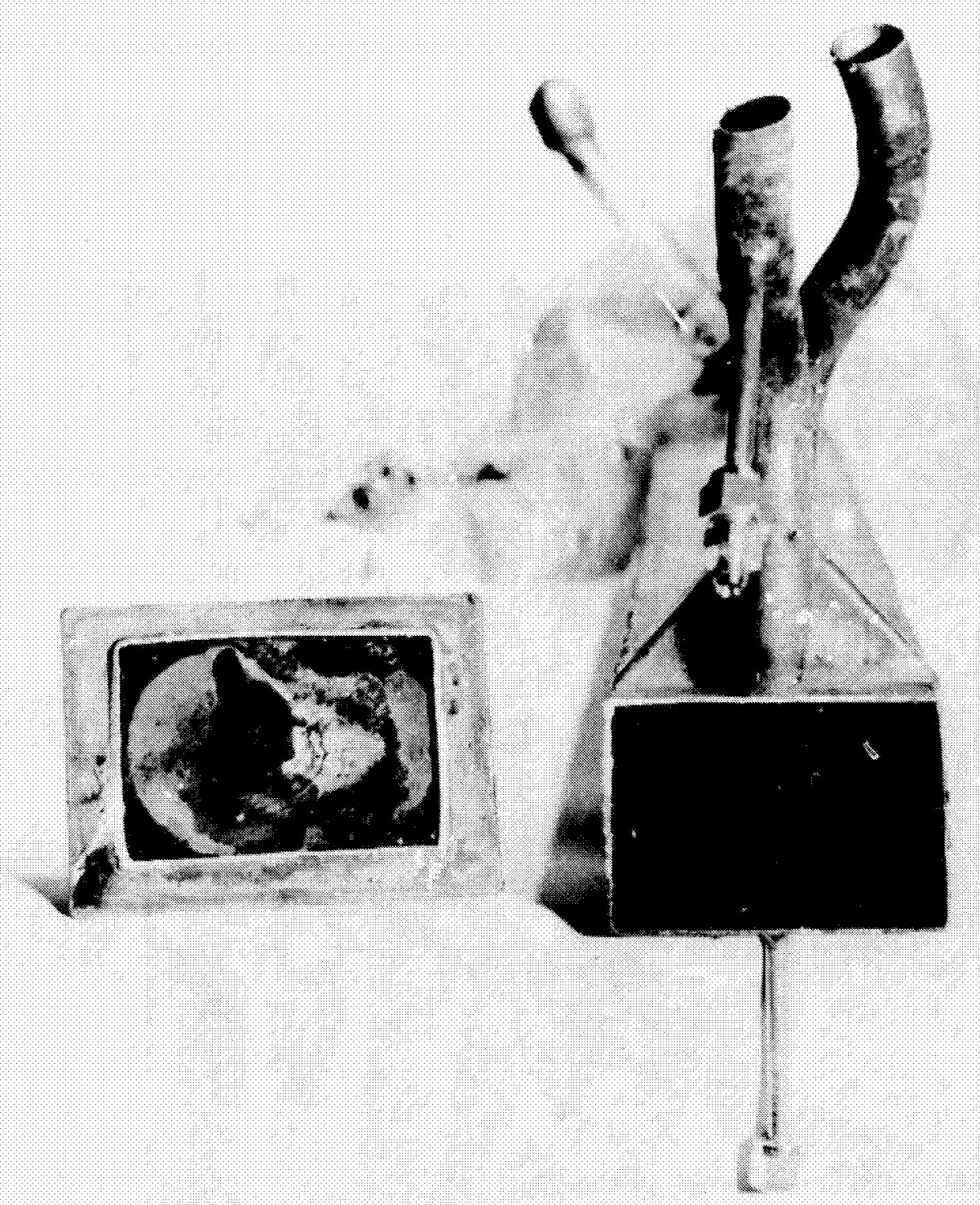

Figure 22.- Carbon build-up in heat exchanger. 


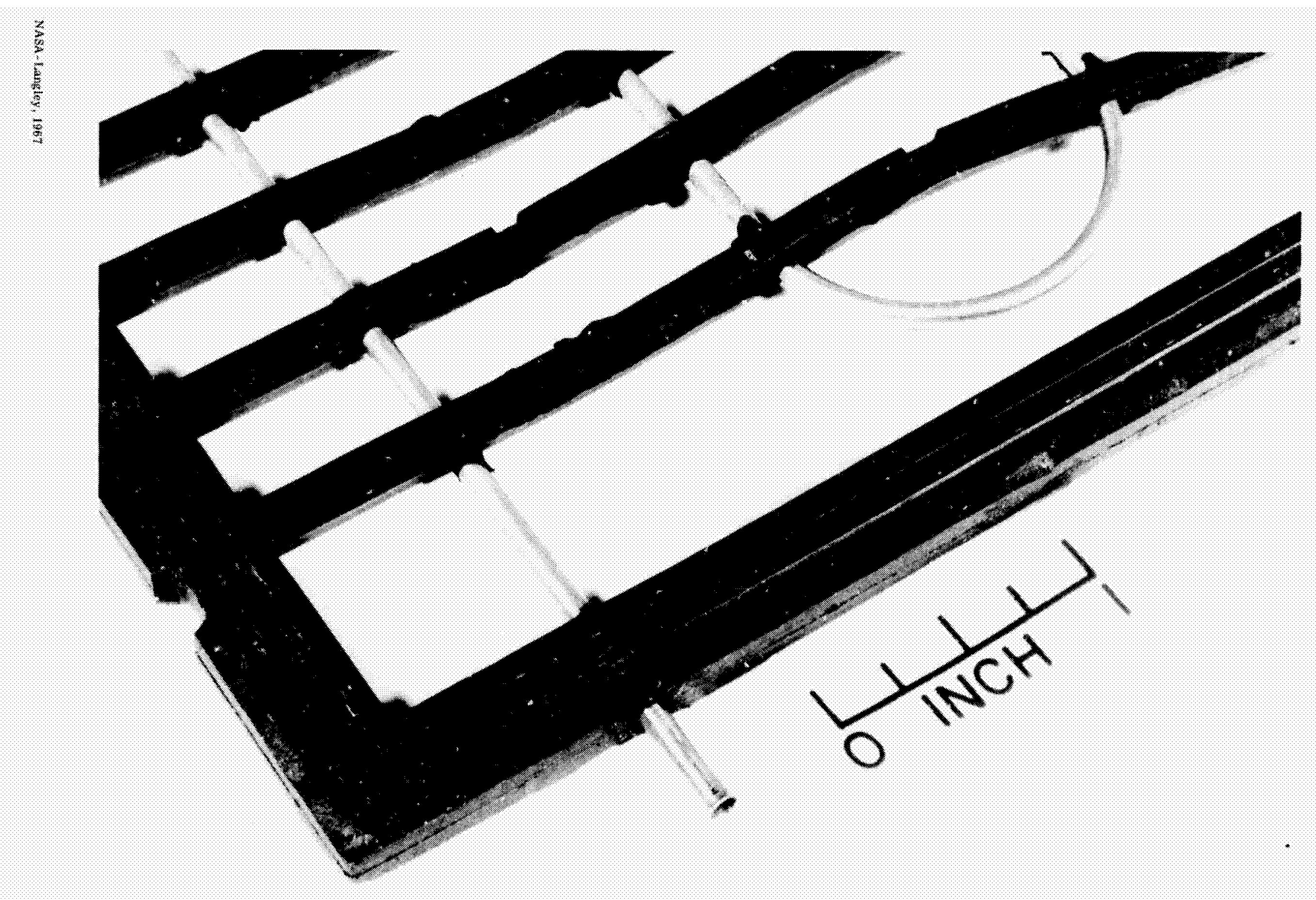

Figure 23.- Flectrolysis cell spacer. 